\title{
Isolation and Diagnosis of Rhizobium Bacteria Isolated from The Root Nodules of Leguminous Plants and Studying Their Plasmid Content.
}

\author{
Wisam Jihad Hisyan *1, Mohammed Abdelilah Al- Shakarchi ${ }^{2}$ \\ ${ }^{1,2}$ Department of Biology, College of Education for Pure Science, University of Mosul, Mosul, Iraq \\ E-mail: ${ }^{1 *}$ basemweasam@gmail.com,${ }^{2}$ dr.mohammedsh@uomosul.edu.iq
}

(Received July 29, 2020; Accepted October 04, 2020; Available online March 01, 2021)

DOI: 10.33899/edusj.2020.127846.1098, (c) 2020, College of Education for Pure Science, University of Mosul.

This is an open access article under the CC BY 4.0 license (http://creativecommons.org/licenses/by/4.0/).

\begin{abstract}
The study included thirty-six isolates of rhizobia bacteria were isolated from the nodules located on the roots of nine types of leguminous family plants that were planted in four areas of the city of Mosul for the winter agricultural season for the year 2020-2019, where they studied the phenotypic and agricultural characteristics of the isolated bacteria in addition to a study of resistance and sensitivity to the isolates of rhizobia bacteria. The study included ten antibiotics, and resistance ratios differed between isolates groups, where the highest resistance rate for residual bacteria isolates was $100 \%$ for Nystatin and Amoxicillin, and the lowest resistance was for Tetracycline and Streptomycin, as it reached $22.2 \%$. As for the rest of the antibiotics, there is a difference between that. As for heavy metal salts, all the isolates of rhizobia bacteria under study were resistant to both $\mathrm{CdCl}_{2}$ chloride and $\mathrm{CoCl}_{2}$ cobalt by $100 \%$, while their resistance to nickel chloride $\mathrm{NiCl}_{2}$ was $77.7 \%$ and the lowest resistance to heavy metal was mercury chloride $\mathrm{HgCl}_{2}$, reaching 33.3\%. The plasmid DNA content was described for the studied isolates, as the results showed that there are two types of plasmid DNA bundles, the first type close to large-scale gel drilling called Mega plasmid represents symbiotic plasmids that carry the genes of contract formation and nitrogen fixation and the second type moves far from the gel drilling and they are sizes small equal representing non-symbiotic plasmids.
\end{abstract}

Keywords: Rhizobium, Symbiosis ,Antibiotics , Heavy Metals , Plasmids.

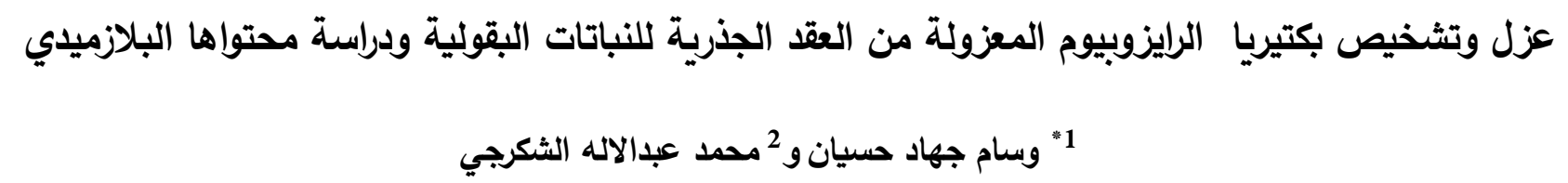

2,1 قسم علوم الحياة, كلية التربية للعلوم الصرفة, جامعة الموصل, الموصل, العراق

الخلاصة

تضـــت الدراسـة عزل ســتة وثلاثين عزلة لبكتيريا الرايزوبيا من العقد الموجودة على جذور نباتات البرسـيم والجت والحلبة

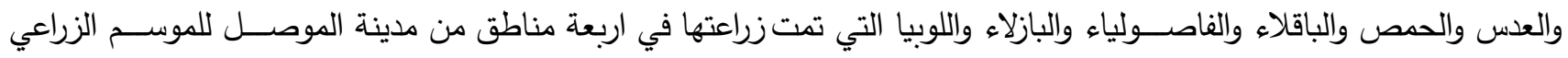

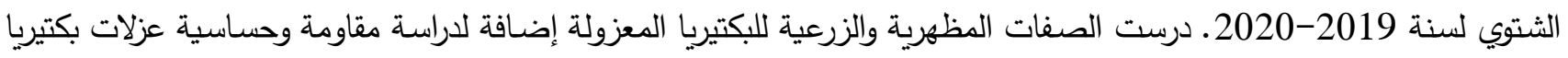

الرايزوبيا المشـولة بالدراسـة لعشـرة مضـادات حيوية واختلفت نسـب المقاومة بين مجاميع العزلات حيث كانت ألعلى نسـبة مقاومة

100\% للمضــادين Amoxicillin Nystatin واقل نسـبة مقاومة 22.2\% للمضـادين Tetracycline و Streptomycin اما 
بقية المضـادات الحيوية فتفاوتت مابين ذلك. اما بالنسبة لاملاح المعادن الثقيلة فقد كانت جميع عزلات بكتيريا الرايزوبيا قيد الدراسـة مقاومة لكل من كلوريد الكادميوم

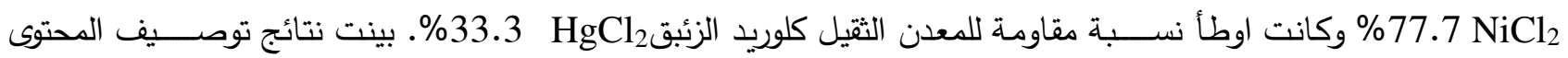

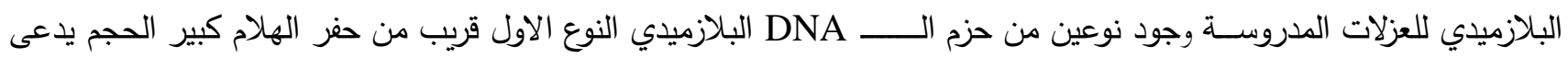

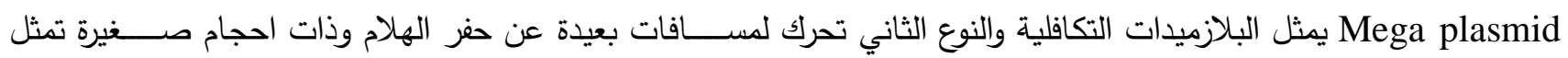
البلازميدات غير التكافلية.

كلمات مفتاحية : الرايزوبيوم ، العلاقة التعايثية ، المضادات الحيوية ، المعادن الثقيلة ، البلازميدات.

\section{المقدمة}

البقوليات Legumes هي نباتات تعود لعائلة الــ Fabaceae او Leguminaceae ذات الانتشار الواسع مقارنة بالعوائل النباتبة الاخرى، وتعتبر مصدر الغذاء الاسساسي بعد الحبوب وفي علم التصنيف التقليدي او الاعتيادي تعد ثالث اكبر عائلة نباتية

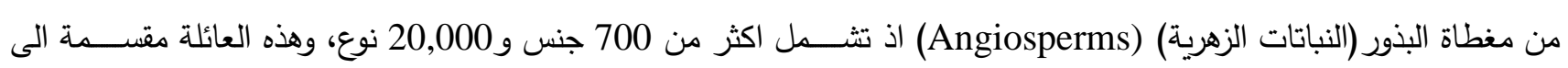

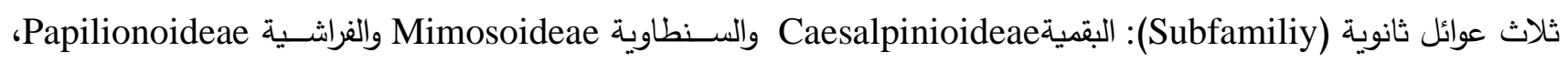
ولأفراد هذه العوائل الثانوية القدرة على تكوين علاقة تعايثـــية مع البكتريا المثبتة للنيتروجين الجوي والموجودة في العائلة الثانوية Papilionoideae


Allorhizobium, Sinorhizobium , Mesorhizobium , Bradyrhizobium, البكتريا على تثبيت النتروجين عن طريق تكوين عقد في جذور النباتات البقولية [2]. تكون افراد هذه العائلة عبارة عن بكتيريا سالبة لصبغة كرام، هوائية واختيارية، عضوية التغذية [3] عصوية الثكل غير مكونة للسبورات تستوطن التربة تتواجد بشكل مفرد او بشكل ازواج وتتحرك باسـواط محيطية او قطبية [4]. تنمو بشكل مستعمرات بيضـاء لزجة على الاوسـاط الغذائية الصلبة الحاوية على خلاصــة

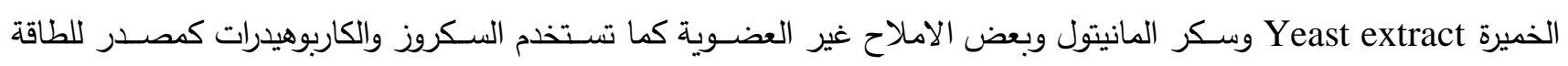

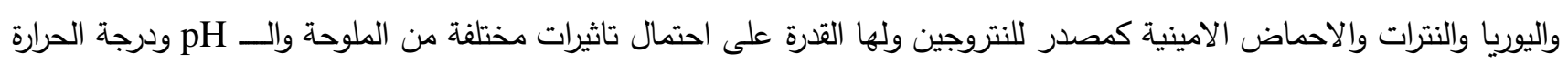

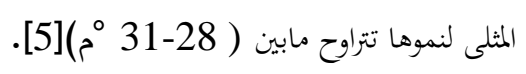

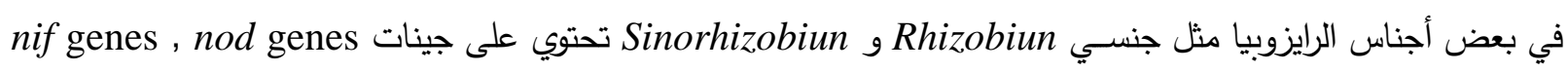
و fix genes موجودة على بلازميد يطلق عليه البلازميد التكافلي Symbiotic plasmid ويطلق عادة على هذه البلازميدات الاكبر من وجد ان هذه لبلازميدات تكون اقل حجما وأكثر عدداً في كل من بكتريا Reguminosarum الســلالة 3841 و بكتيريا

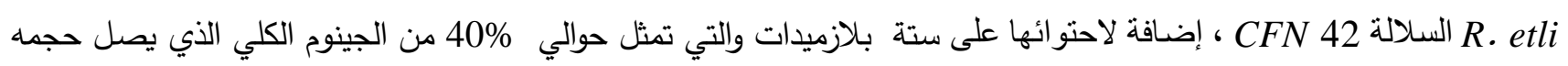

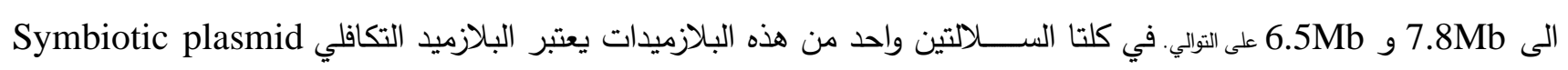

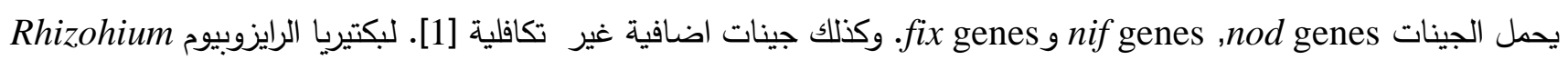

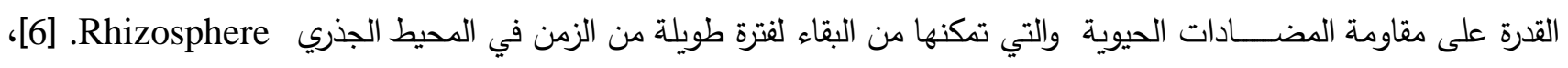

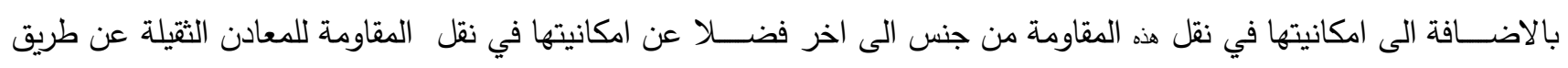

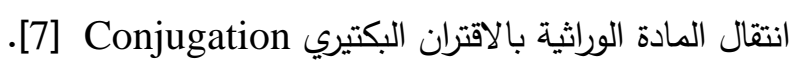


تهذف الدراســة إلى عزل الانواع البكتيرية العائدة لجنس الــــ Rhizobium من بعض النباتات البقولية والمزروعة في اربعة

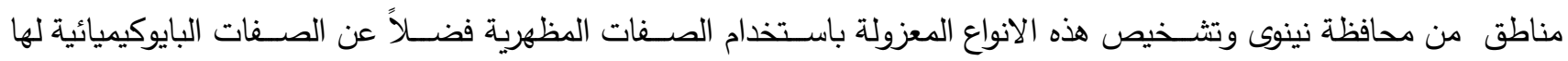

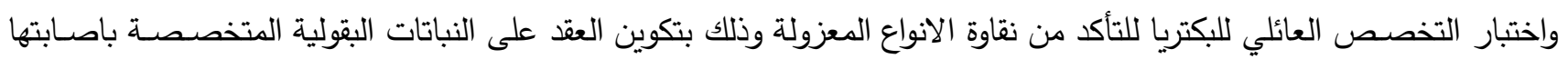

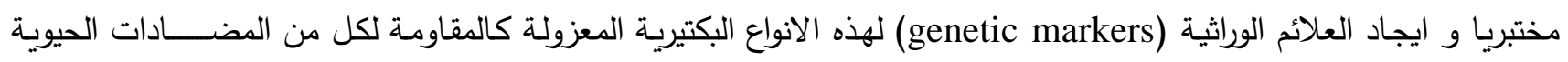
والمعادن الثقيلة، و التحري عن الـDNA البلازميدي في عزلات بكتريا الرايزوبيا.

مواد وطرائق البحث:

عزل بكتيريا الرايزوبيوم من العقد الجذرية للنباتات البقولية:

:Isolation of Rhizobium Bacteria from the Root Nodes of Leguminous Plants

عزلت بكتيريا الرايزوبيوم من العقد المتكونة على جذور النباتات البقولية المزروعة في اربعة مواقع من محافظة نينوى ( وهي

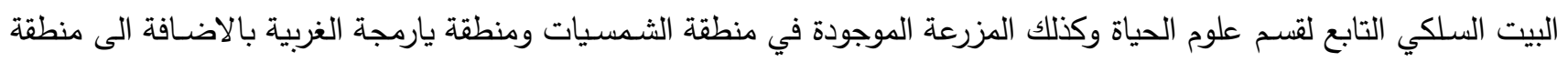

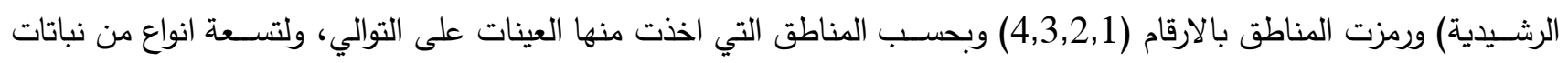

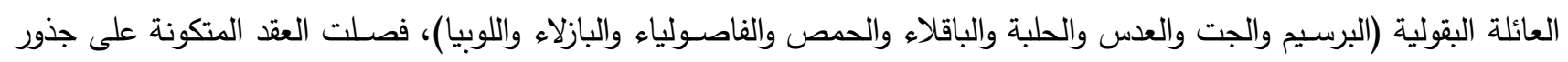

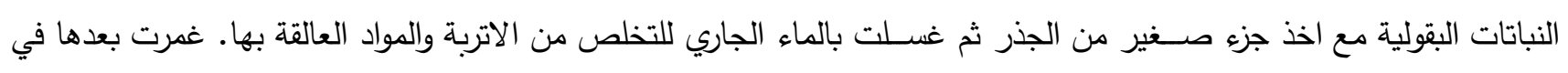

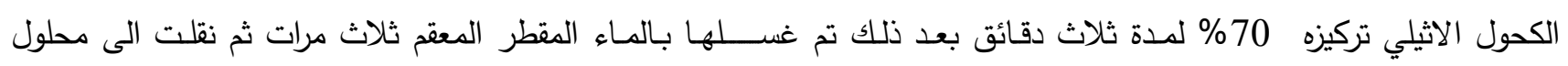

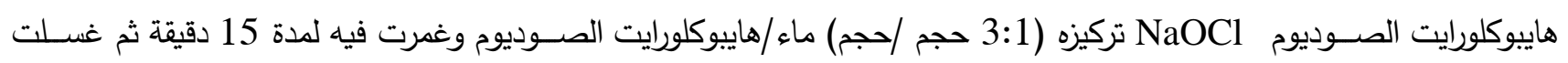

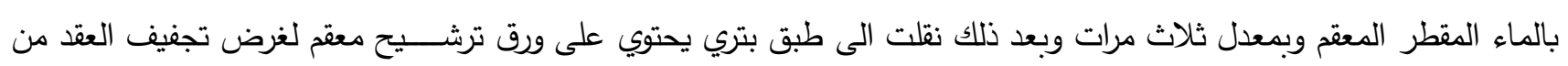

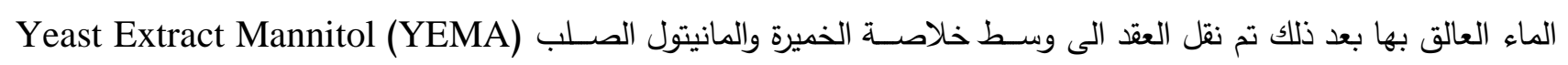
غرام (15:Agar $0.5: \mathrm{K}_{2} \mathrm{HPO}_{4}$ و 0.2 : $\mathrm{MgSO}_{4} .7 \mathrm{H}_{2} \mathrm{O}$, 0.1 : NaCl 10:Mannitol 0.4:Yeast extract) Agar

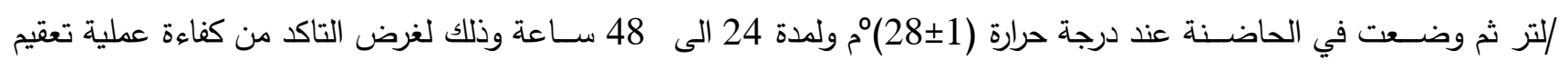
العقد الجذرية [8].

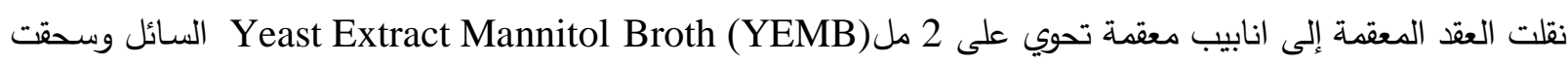

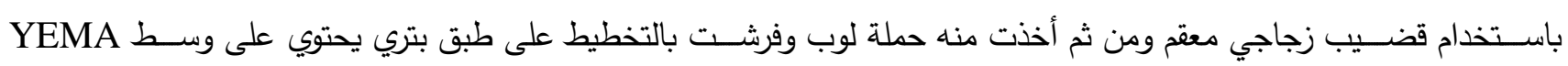

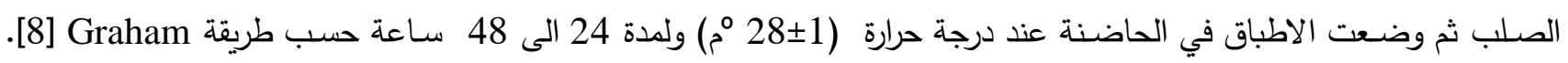

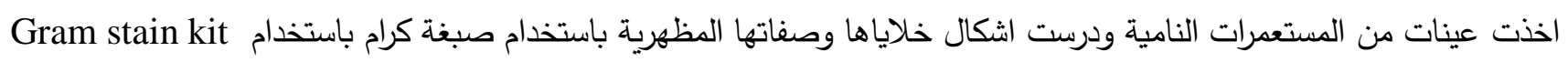
فحصــ بالعدسـة الزيتية (100x) للمجهر الضــوئي المركب Vimedia) المضيف النباتي الى تسعة مجاميع مع وضع رمز لكل مجموعة تم الحصول عليها من النباتات البقولية وكما مبينة بالجدول (1).

\begin{tabular}{|c|c|c|c|c|c|c|c|c|c|}
\hline اللوبيا & البازلاء & الفاصولياء & الباقلاء & الحلبة & العدس & الحمص & البرسيم & الجت & المضيف النباتي \\
\hline RhR & $\mathrm{RhP}$ & $\mathrm{RhPh}$ & RhV & RhG & $\mathrm{RhC}$ & RhA & RhM & RhS & رمز العزلة البكتيرية \\
\hline
\end{tabular}

أجري اختبار التخصص العائلي لكل عزلة وذلك باخذ حملة لوب من المستعمرات المعزولة لتلقيح 50 مل من وسط YEM السائل باستخدام دوارق زجاجية ولمدة 48 ساعة ومن ثم طردت مركزيا للحصول على راسب من البكتريا.

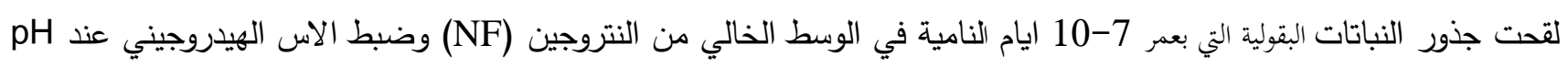


6.6.6 باستخدام اللقاح البكتيري المعد من الخطوة السابقة وحسب طريقة Singh واخرون [13] للتاكد من مقدرة العزلة البكتيرية على تكوين العقد الجذرية على المضيف النباتي الخاص بها. حضر الوسط عن طريق اذابة المكونات المذكورة في الجدول رقم (2)

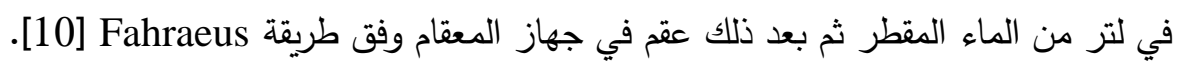
جدول رقم (2) مكونات وسط NFen Fitrogen

\begin{tabular}{|c|c|}
\hline التركيز ملغم /لتر & التر \\
\hline 120 & $\mathrm{MgSO}_{4} .7 \mathrm{H}_{2} \mathrm{O}$ \\
\hline 150 & $\mathrm{Na}_{2} \mathrm{HPO}_{4}$ \\
\hline 100 & $\mathrm{KH}_{2} \mathrm{PO}_{4}$ \\
\hline 132 & $\mathrm{CaCl}_{2} .2 \mathrm{H}_{2} \mathrm{O}$ \\
\hline 0.062 & $\mathrm{H}_{3} \mathrm{BO}_{3}$ \\
\hline 0.05 & $\mathrm{Fe} \mathrm{citrate}\left(\mathrm{FeC}_{6} \mathrm{H}_{6} \mathrm{O}_{7}\right)$ \\
\hline 0.11 & $\mathrm{MnSO}_{4} .2 \mathrm{H}_{2} \mathrm{O}$ \\
\hline 0.28 & $\mathrm{ZnSO}_{4} .7 \mathrm{H}_{2} \mathrm{O}$ \\
\hline 0.024 & $\mathrm{CoCl}_{2} .6 \mathrm{H}_{2} \mathrm{O}$ \\
\hline 0.025 & $\mathrm{CuSO}_{4} .5 \mathrm{H}_{2} \mathrm{O}$ \\
\hline 0.024 & $\mathrm{NaMoO}_{4} .2 \mathrm{H}_{2} \mathrm{O}$ \\
\hline 8000 & $\mathrm{Agar}$ \\
\hline
\end{tabular}

Heavy Metal Medium

وسط المعادن الثقيلة:

تم تحضير الوسط باضافة املاح المعادن الثقيلة(

وسط خلاصة الخميرة والمانيتول المعقم والمبرد الى درجة حرارة( 45-50 )ْم وبالتتراكيز المـبينة في الجدول رقم (3)[11] ـ

جدول رقم (3): التراكيز الخزينة والنهائية لاملاح المعادن الثقيلة

\begin{tabular}{|c|c|c|c|c|c|}
\hline المذيب & $\begin{array}{c}\text { التركيز النهائي } \\
\text { mg/ml }\end{array}$ & mg/ml التركيز الخزين & رمز المعدن & المعدن الثقيل & $ت$ \\
\hline ماء مقطر معقم & 25 & 25 & $\mathrm{HgCl}_{2}$ & كلوريد الزئبق & 1 \\
\hline ماء مقطر معقم & 25 & 25 & $\mathrm{NiCl}_{2}$ & كلوريد النيكل & 2 \\
\hline ماء مقطر معقم & 25 & 25 & $\mathrm{CdCl}_{2}$ & كلوريد الكادميوم & 3 \\
\hline ماء مقطر معقم & 25 & 25 & $\mathrm{CoCl}_{2}$ & كلوريد الكوبلت & 4 \\
\hline
\end{tabular}

Antibiotic Test Medium

وسط اختبار المضادات الحيوية:

حضر وسط الاكار المغذي وعقم بجهاز الاوتوكليف وبعد تبريد الوسط الى درجة حرارة (45-50)؛ أضيف المضاد المضاد

الحيوي الى الوسط وبتركيز نهائي مايكروغرام/ مليلتر والماخوذ من محلول الخزين لكل مضاد حيوي كما هو مبين في الجدول رقم (4) للمضادات الحيوية الخزينة والمذيبات الخاصة بها [12]. علما ان المضادات الحيوية تم الحصول علئردئ عليها من شركة دار الدواء الاردنية (DAD ALDawa (Jordan) (DAD) والثركة العامة لصناعة الادوية(سامراء / العراق). وتم تعقيم محاليل المضادات الحيوية الخزينة والنهائية بواسطة Filtre Sirynge بحجم (0.45ر). 
جدول رقم (4): التراكيز الخزينة والنهائية للمضادات الحيوية

\begin{tabular}{|c|c|c|c|c|c|}
\hline المذيب & التركيز النهائي & mg/ ml التركيز الخزين & 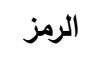 & المضاد الحيوي & 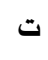 \\
\hline ايثانول مطلق & 30 & 5 & $\mathrm{Cm}$ & Chloramphenicol & 1 \\
\hline ميثانول 100\% & 50 & 5 & Rif & Rifampicin & 2 \\
\hline ايثانول70\% & 10 & 5 & Tc & Tetracycline & 3 \\
\hline ايثانول70\% & 50 & 5 & Nys & Nystatin & 4 \\
\hline ماءمقطر معقم & 50 & 5 & Ap & Ampicillin & 5 \\
\hline ايثانول مطلق & 15 & 10 & Ery & Erythromycin & 6 \\
\hline $0.1 \mathrm{~N} \mathrm{NaOH}$ & 30 & 50 & $\mathrm{Nal}$ & Nalidixic acid & 7 \\
\hline ايثانول 70\% & 50 & 5 & Amo & Amoxicillin & 8 \\
\hline ماء مقطر معقم & 20 & 50 & Str & Streptomycin & 9 \\
\hline ماء مقطر معقم & 50 & 5 & $\mathrm{Ce}$ & Cefixime & 10 \\
\hline
\end{tabular}

الاختبارات البايوكيميائية لعزلات بكتيربا الرايزوبيوم

\section{Biochemical tests for Rhizobium Bacterial Isolates}

اســـتخدمت عدد من الاختبارات البايوكيميائية على الاجناس المختلفة من بكتيريا الرايزوبيا المعزولة من العقد الجذرية لعدد من

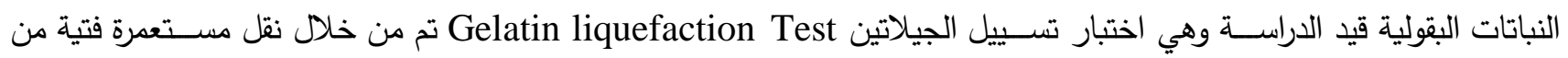

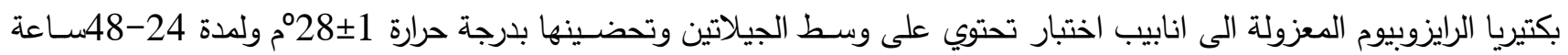

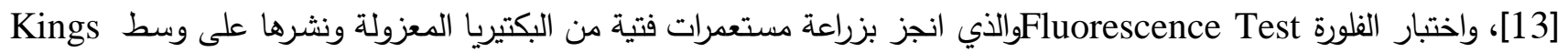

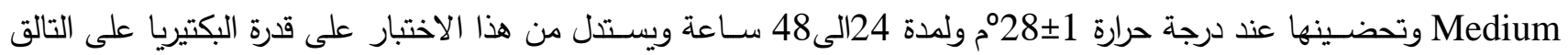
الضوئي بعد تعرضها للاشعة فوق البنفسجية عند الطول الموجي 320nm وذلك حسب طريقة كinghو اخرون [13]، اختبار انتاج انزيم اليوريز Urease Test حيث استخدم اكار اليوريا المعقم لزراعة مستعمرات فتية من عزلات بكتيريا الرايزوبيوم النقية وحضنت

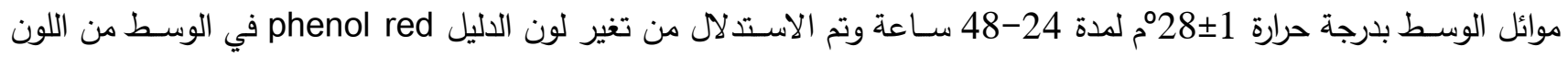

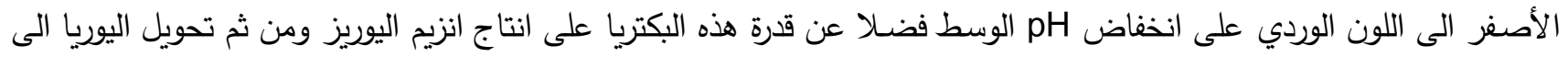
أمونيا [14]، اختبار الكاتاليز Catalase Test اجري هذا الاختبار عن طريق وضـــع مسـتعمرة فتية من بكتيريا الرايزوبيوم المعزولة

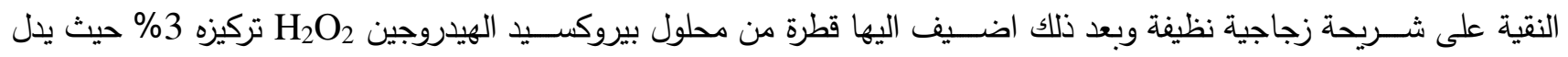

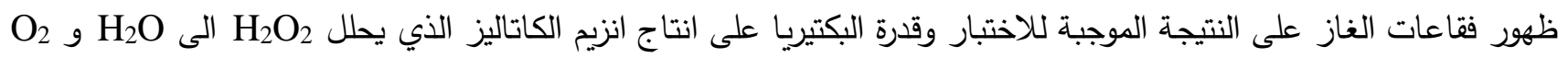
حسـب طريقة Chhetri واخرون [15]، كذلك اسـتخدم اختبار اسـتهلاك السـترات Citrate Utilization Test عن طريق تلقيح وسـطس سـيمون سـتريت اكار Simmons Citrate Agar بمستعمرات فتية من عزلات بكتيريا الرايزوبيوم النقية في انابيب اختبار

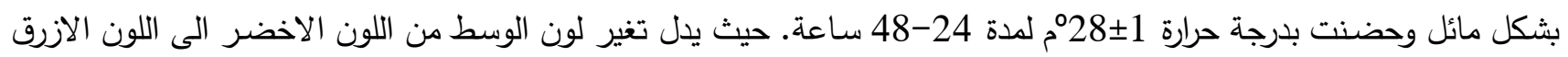

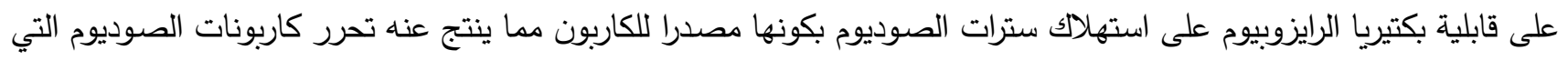

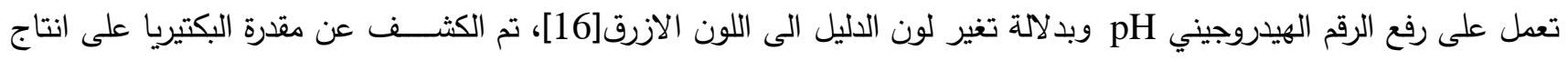

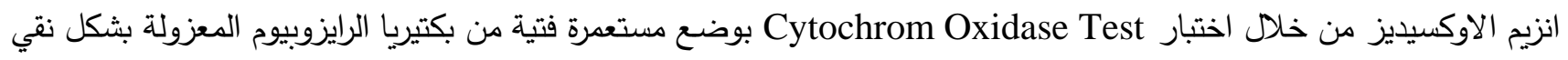

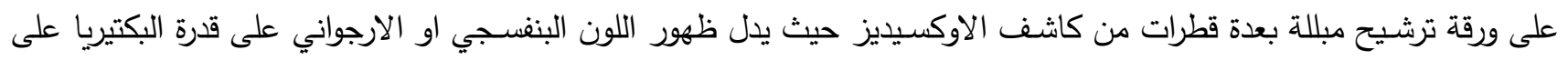


انتاج انزيم Cytochrom Oxidase الذي يؤكســ الكاشـف الى الناتج Indophenol حسـب طريقة Wadhwa واخرون [16]، استخدم اختبار فوكس - بروسكر Voges-Proskuar Test بنقل مستعمرة فتية من عزلات البكتيريا قيد الدراسـة النقية الى وسط فوسط

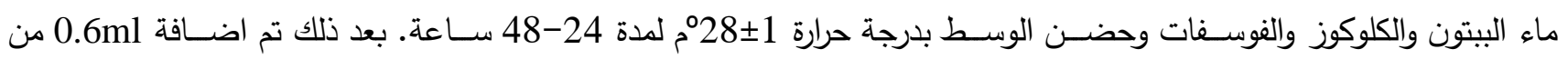

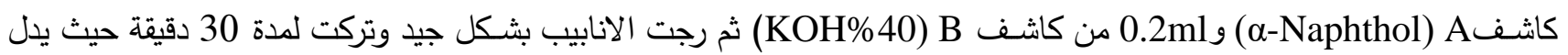

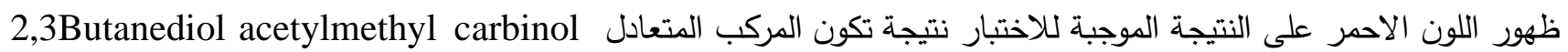
acetion وفق طريقة Sherman Cappuccino [17]، اختبار المثيل الاحمر Methyl Red Test لقعت مجموعة من انابيب اختبار تحوي على وسط ماء البيتون والكلوكوز والفوسفات بمستعرات فتية من عزلات بكتيريا الرايزوبيوم النقية وحضن الوسط بدرجة

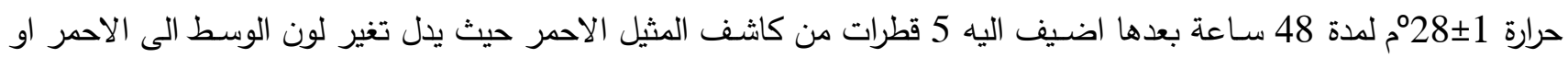
الوردي على قدرة البكتيريا على تخمير الســـكر وانتاج الحامض الذي يعمل على خفض الرقم الهيدروجيني pH الى الى اقل من 4.5 وتكون النتيجة موجبة للاختبار [18]، اختبار انتاج الاندولIndol Production Test حيث اجري هذا الاختبار بتلقيح وســ ماء

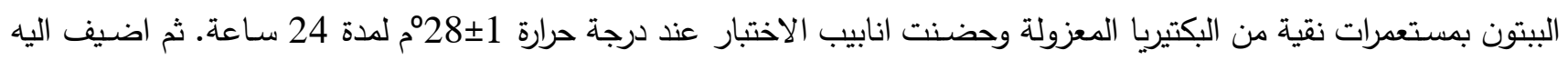
بعدها 5 قطرات من كاثـــف كوفاكس حيث يدل ظهور حلقة حمراء في اعلى طبقة الكحول على قابلية البكتيريا على انتاج الاندول

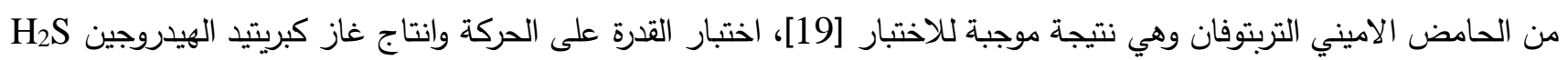

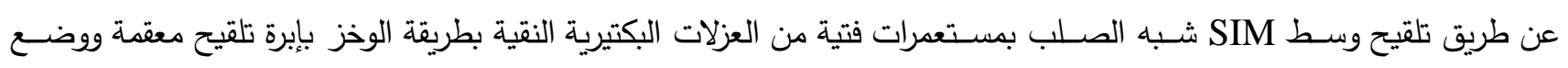

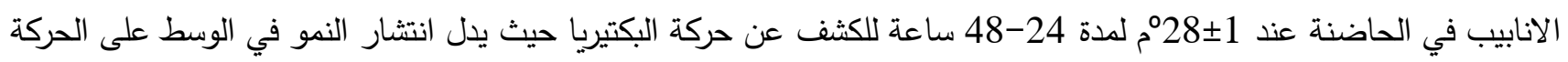

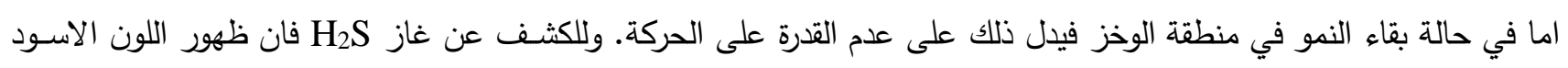
في اســفل انابيب الاختبار يدل على قدرة البكتيريا على انتاج الانزيم Cysteine desulfurase الذي يحلل الحامض الاميني Cysteine

عزل وتنقية محتوى الـ DNA البلازميدي من عزلات بكتيريا الـRhizobium باستخدام المواد الجاهزة المجهزة من قبل شركة Promega Isolation and purification of the plasmid DNA content from Rhizobium isolates using the readymade materials prepared by Promega USA

رسبت الخلايا البكتيرية للمزرعة البكتيرية السائلة المنماة لمدة 24-48 سـاعة باستخدام انبوب طرد مركزي (ابندوف) بحجم

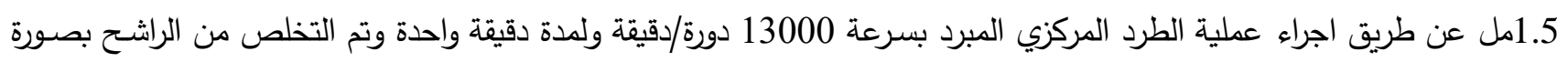


من محلول pH 8) 1M Tris-HCl)، 0.8 مل من محلول 0.25 M EDTA (pH 8) المعقم، وأكمل الحجم الى 20 مل بالماء

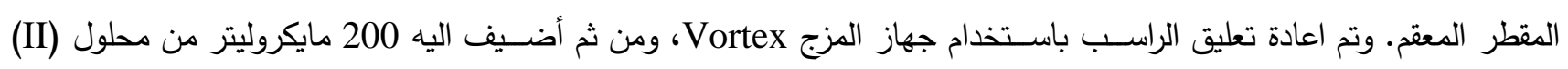

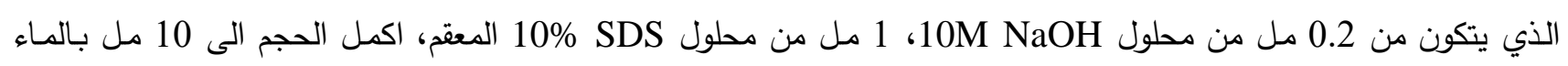

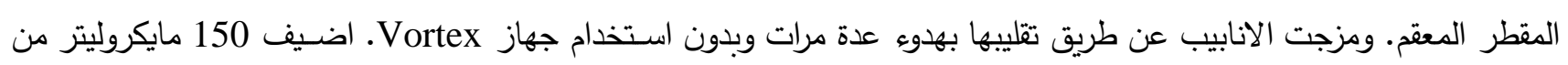

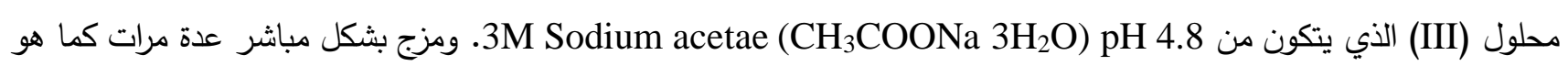

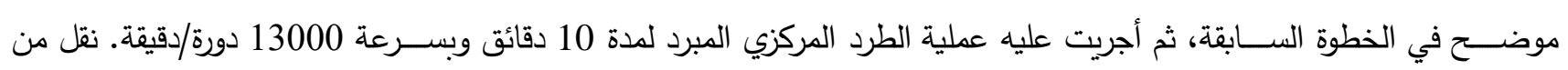

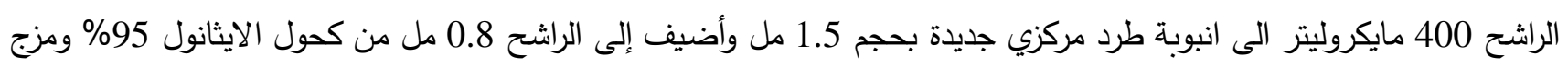
عن طريق تقليب الانابيب ومن ثم ترك بدرجة حرارة الغرفة لمدة خمسة دقائق. 
وأجريت عليه عملية الطرد المركزي وبســرعة قصـــى (13000 دورة/دقيقة) لمدة 10دقائق وبعدها تم التخلص من الراشــح

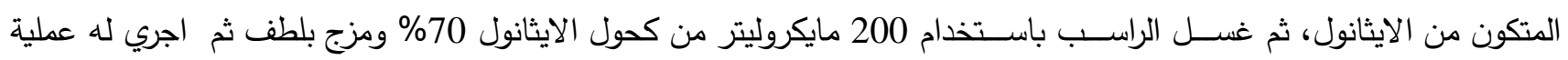
الطرد المركزي لمدة 5 دقائق للتخلص من الايثانول. ثم بعد ذلك وضـع الانبوب بصـورة مقلوبة على ورق تتشـيف للتخلص من بقايا

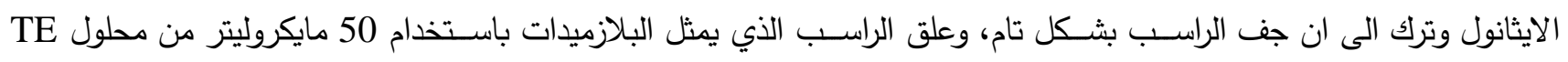
وحفظ لحين الاستخدام. النتائج والمناقشة

الاختبارات التشخيصية لبكتيريا الرايزوبيا المعزولة المستخدمة في الاراسة

\section{Diagnostic Tests For Rhizobia Isolated Bacteria Understudy} 1- اختبار التخصص العائلي لعزلات بكتيريا الرايزوبيا

\section{Family specialty test for isolates of Rhizobia bacteria}

تم تحضير اللقاح البكتيري من بكتيريا الرايزوبيا بعد عزلها من العقد الجذرية للنباتات البقولية باستخدام وسط خلاصة الخميرة والمانيتول السائل بEMB)Yeast Extract Mannitol Broth) في قناني زجاجية بحجم 20 مل ثم حضن الوسط في الحاضنة

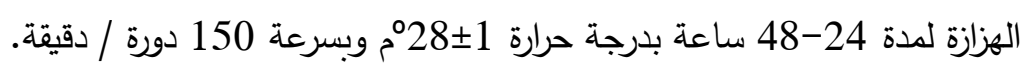

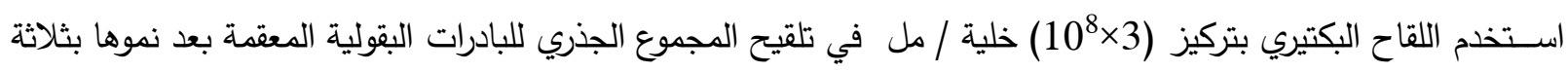

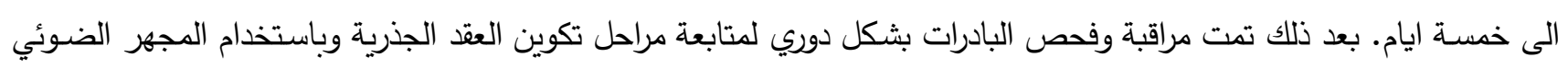



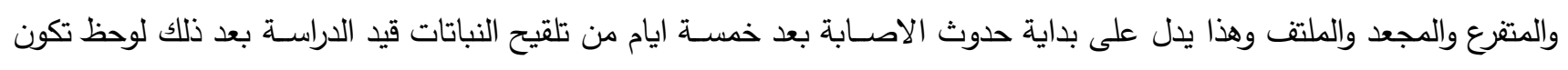

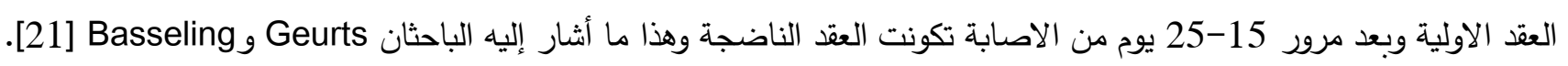
من خلال دراسـة اشكال العقد الناضجة المتكونة على جذور النباتات الملقحة وجد انها تتباين بين مجاميع بكتيريا الرايزوبيا

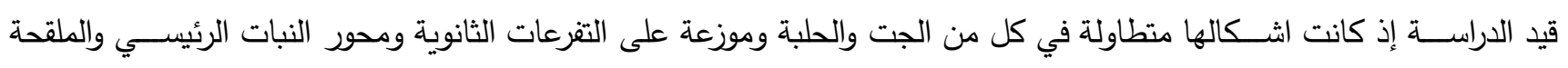
بواسطة مجاميع البكتريا RhS وRhG التي سبق ان تم الحصول عليها من عقد نباتات الجت والحلبة على التوالي. و اشكال كروية منتظمة ناتجة على جذور نباتات العدس والحمص والباقلاء والفاصولياء والبرسيم وتفرعاتها الثانوية والتي لقحت سابقا بواسطة بكتيريا الرايزوبيا للمجاميع RhC و RhA و RhPh و RhM و على التوالي. في حين كانت العقد المتكونة على جذور نباتات البازلاء

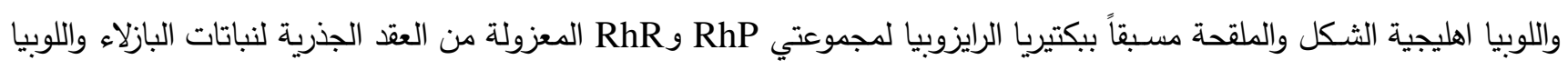

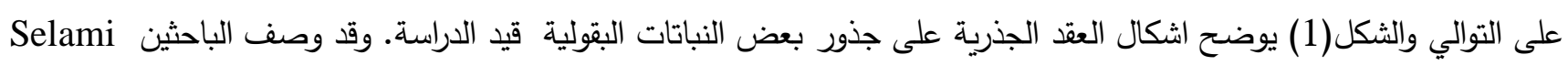
واخرون [22] بان اشكال العقد تكون طولانية عند دراستهم شكل العقد وتثـريحها في نبات Retma monosperma في الجزائر .

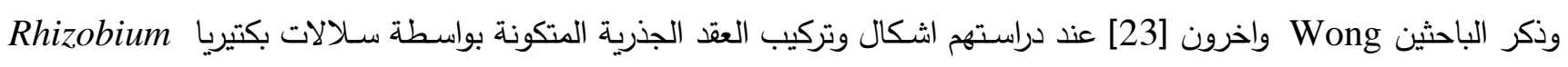
Agrobacterium meliloti التلقيح ثم تصبح اسطوانية بعد ثلاثة اسابيع او اكثر. 


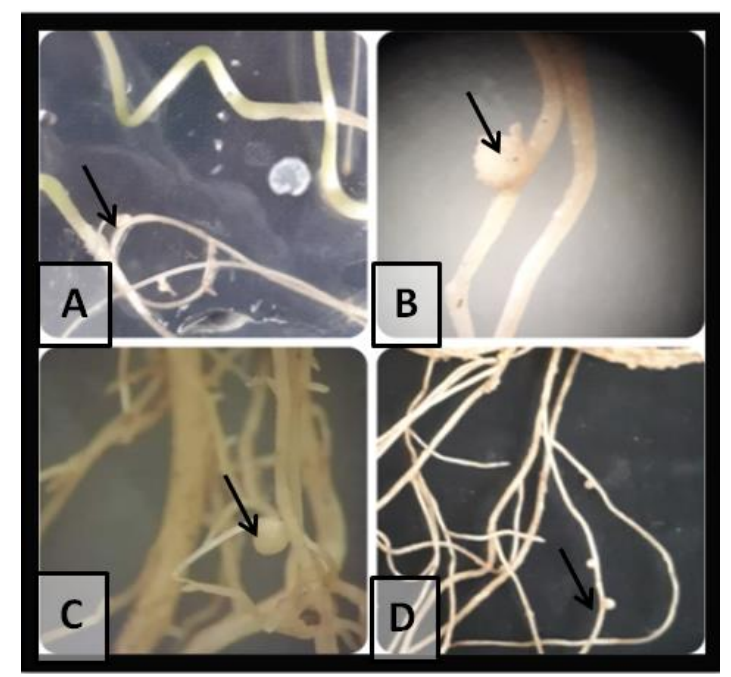

شكل رقم (1) يوضح اشكال العقد الجذرية المتكونة على جذور عدد من النباتات البقولية الملقحة مختبرياً.

A : العقد الجذرية المتكونة على جذور نبات الجت (الجزء الموشر).

B : العقد الجذرية المتكونة على جذور نبات البازلاء (الجزء الموشر).

C C العقد الجذرية المتكونة على جذور نبات الباقلاء (الجزء الموشر).

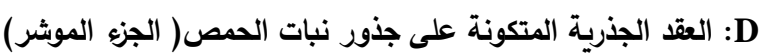

الصفات المظهرية والززرعية لعزلات بكتيريا الريزوبيا

\section{Morphological and Cultural Characters for Isolated Rhizobial Bacteria}

ظهرت مستعمرات بكتيريا الرايزوبيا النامية على وسط YEMA بالوان متفاوتة ما بين الكريمية والعاجية ذات حافات ملسـاء ولزجة القوام ودائرية. ولوحظ ان المستعمرات تتتج سكريات متعددة خارج خلوية وبكميات مذهلة على هذه الاوسـاط الغنية بالكاربون

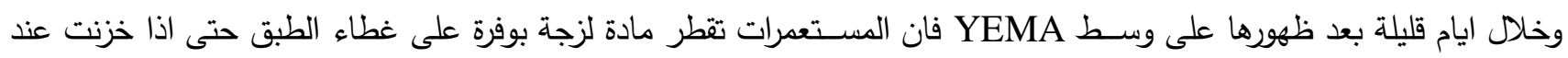

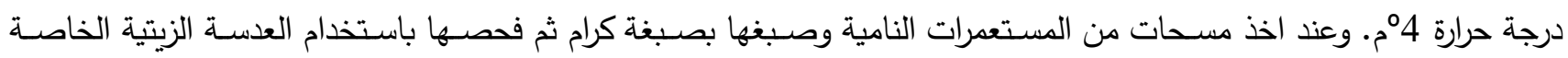

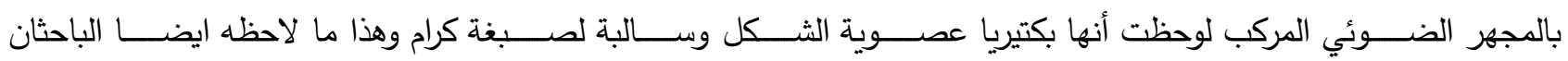

.[1] Rajkumar gIyer

بينما كانت صـفة اللزوجة في مجاميع بكتيريا الجت والحلبة RhS و RhG قليلة ومثـابهة للبكتيريا التي قام بعزلها الباحثين Hussain

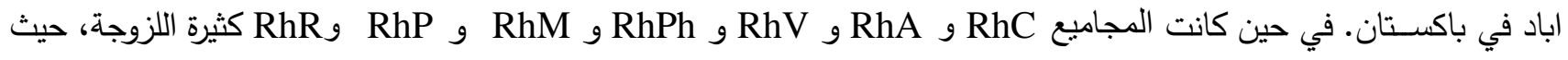

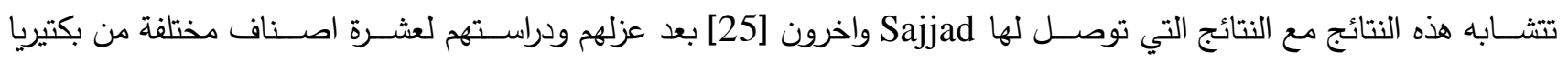
الرايزوبيوم العائدة لنبات العدس البقولي الذي ينمو في اماكن مختلفة من اقليم البنجاب في باكستان حيث كانت المستعمرات صمغية كثيرة اللزوجة وشفافة دائرية مع حافات ملساء او ناعمة وكانت جميع السلالات سالبة وعصوية الثكل عند صبغها بصبغة كنئ كرام.

Biochemical Tests الاختبارات البايوكيميائية

اجريت عدد من الاختبارات البايوكيميائية لعزلات بكتيريا الرايزوبيا والموضـــــــتائجها في الجدول (5)، ووجد ان مجموعة

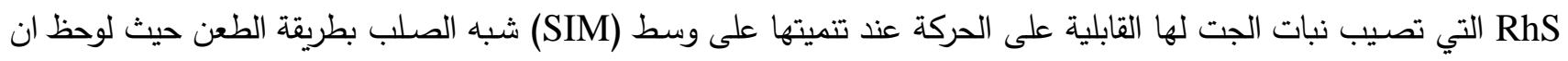

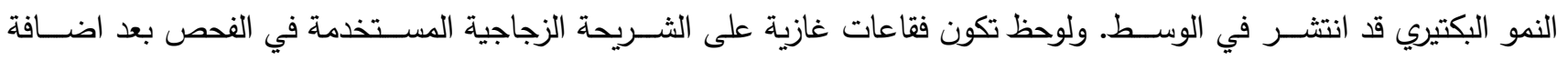




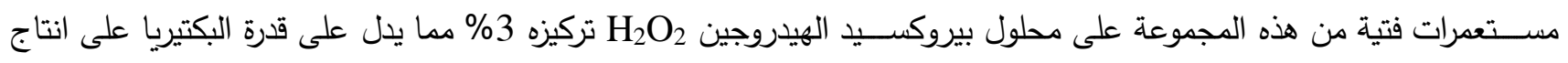

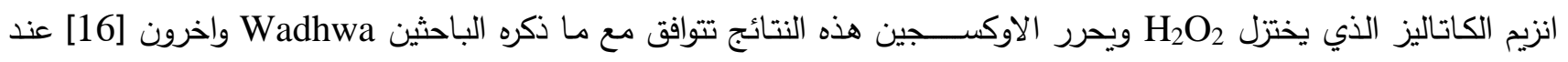

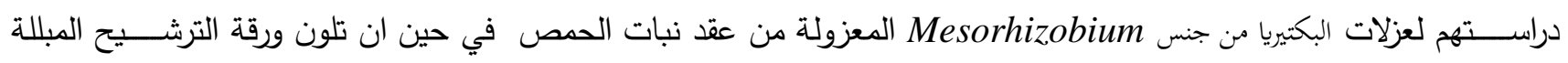


في حين أن اختبارات الفوكس بروسكر واستهالك السترات وانتاج انزيم الجيلاتينيز وكذلك انتاج كانت نتيجتها سالبة وهذه النتيجة تتوافق مع ماتوصل اليه الباحثين Deka و Azad [26]عند دراستهم لـ157 عزلة من بكتيريا الرايزوبيوم المعزولة من ستة



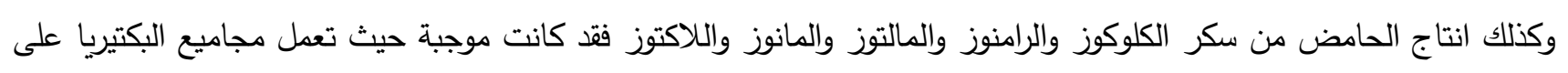

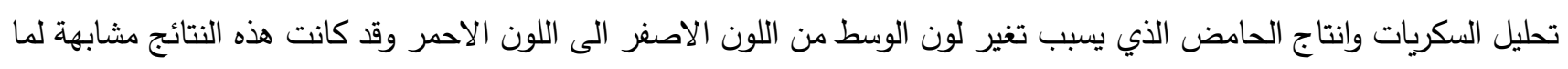

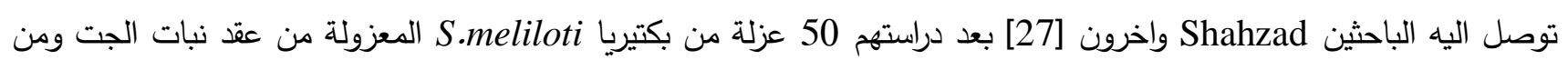
خلال مقدرتها على تحليل السكريات وتغير لون الوسط إلى اللون الاحمر .

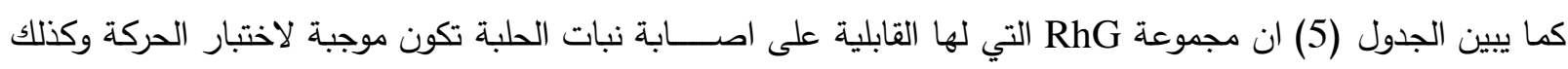

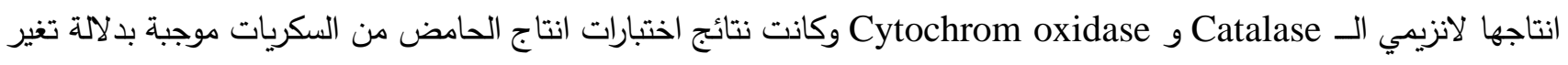

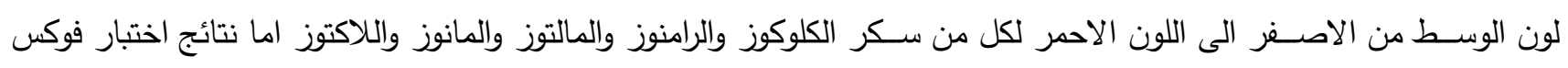
بروسكر واستهلاك السترات وانزيم الجيلاتينيز وانتاج H فقد كانت سـالبة. في حين ان نتيجة اختبار الاندول وانتاج انزيم اليوريز

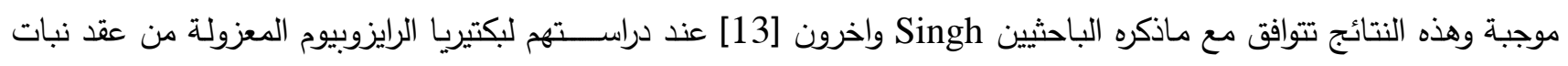

ويوضـــح الجدول(5) ان مجموعة بكتيريا الرايزوبيوم RhC المعزولة من العقد الجذرية لنبات العدس لها القابلية على الحركة وكذلك كانت منتجة لانزيمي الكاتاليز والاوكســيديز وتكون هذه المجموعة موجبة لاختبار الاندول وانتاج انزيم اليوريز وكذلك انتاج

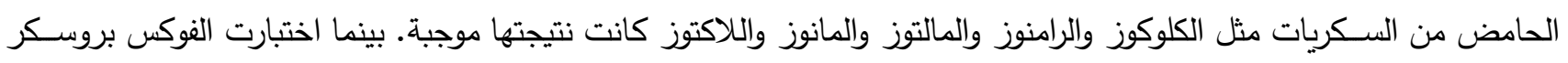

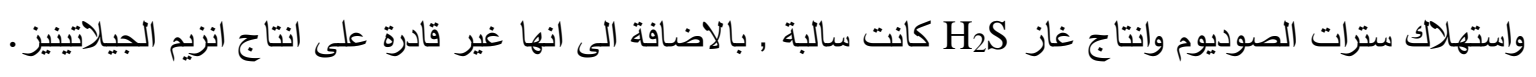
كما يوضـح الجدول (5) ان مجموعة بكتيريا الرايزوبيوم RhA التي تم الحصول عليها من العقد الجذرية لنبات الحمص انها

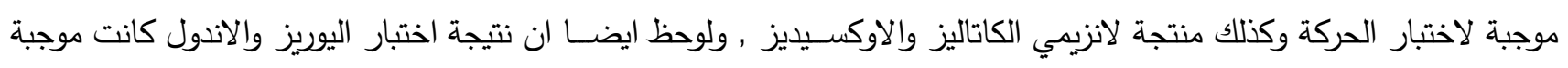

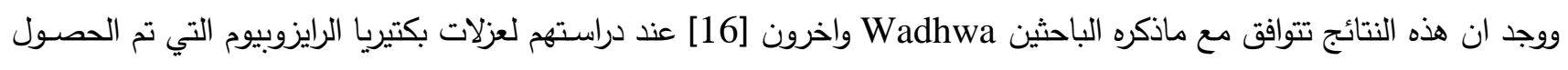

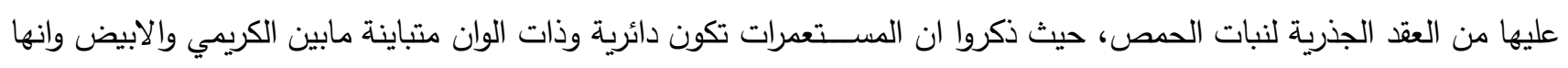

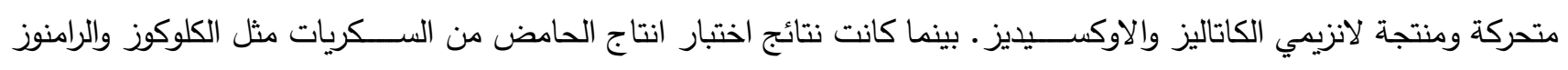

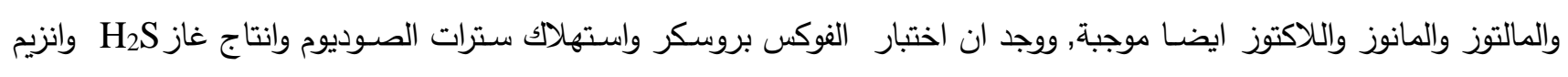
الجيلاتينيز سالبة وهذه النتيجة تتوافق مع ماوجده الباحثين Roychowdhury واخرون [28] عند دراستهم لعزلات بكتيريا الرايزوبيوم المعزولة من عقد نبات الحمص.

كذلك عند ملاحظتنا للجدول (5) فان مجموعة RhV التي تصــيب نباتات الباقلاء لها القابلية على الحركة ومنتجة لانزيمي

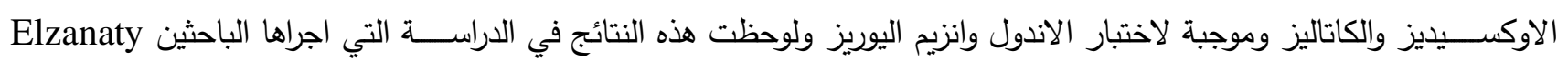

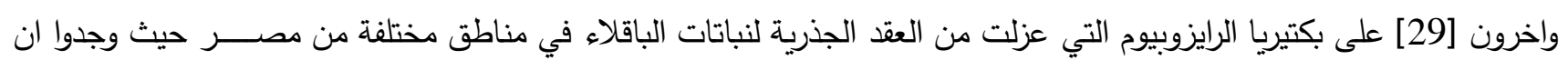

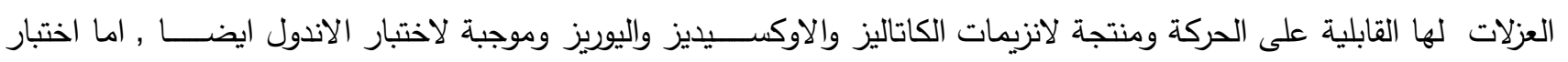


الفوكس بروسـكر واسـتهلاك سـترات الصــوديوم وانتاج غاز H2S وانزيم الجيلاتينيز فقد كانت سـالبة في حين ان نتائج الاختبار

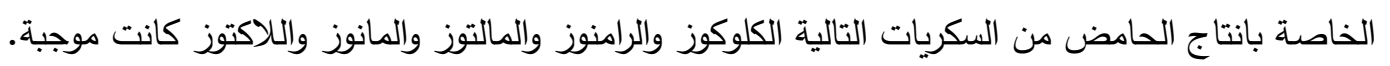
أما بقية مجاميع بكتيريا الرايزوبيوم مثل RhR و RhP , RhPh, RhM والتي عزلت من العقد الجذرية لنباتات البرســـيم

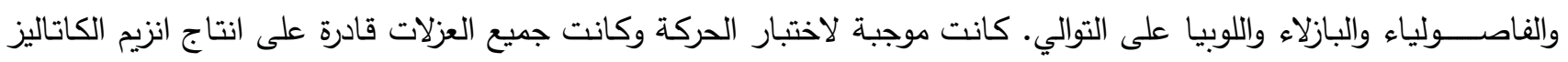
والاوكسيديز وكذلك منتجة للاندول ولها القابلية على انتاج انزيم اليوريز وهذه النتيجة توافق ماتوصل الئليه واليه الباحثين Al-Mujahidy

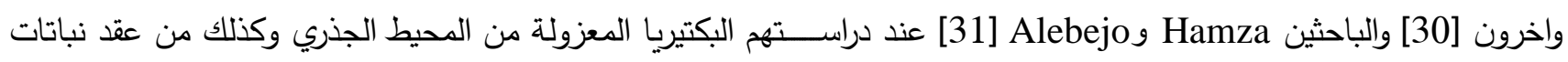
اللوبيا واللبلاب. بينما كانت كل من اختبارات الفوكس بروسكور واستهلاك السترات وانتاج انزيم الجيلاتينيز وغاز

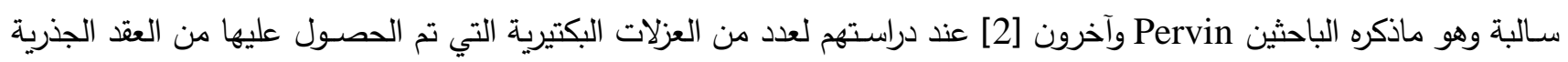

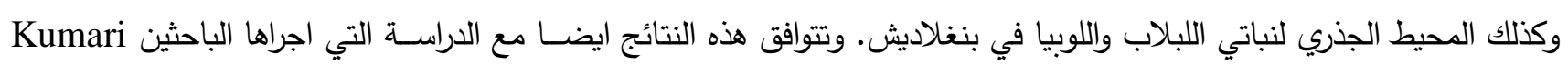

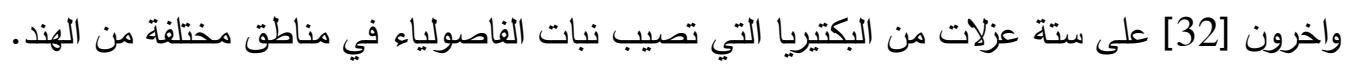
يتضـح أيضـاً من الجدول (5) انه عند القيام بتتمية مجاميع بكتيريا الرايزوبيا RhPh, RhV, RhA, RhC , RhG, RhS ولياء RhR و RhP, RhM,

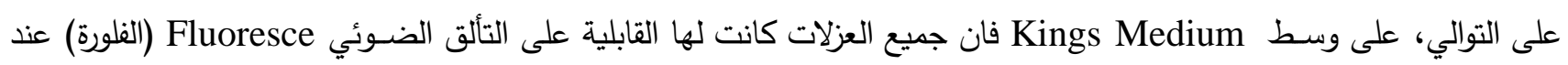
تعريضـها للأشعة فوق البنفسية بواسطة جهاز UV light Transilluminator عند طول موجي 320nm. وهذه النتيجة توافق



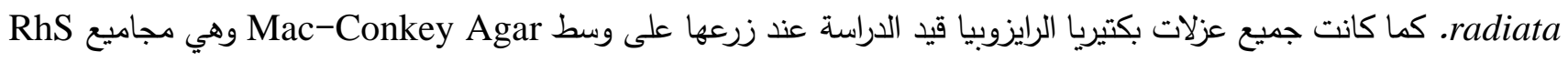

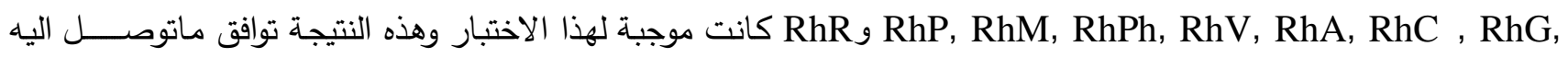
الباحثين Kumari واخرون [32].

جدول رقم (5) الاختبارات البايوكيميائية لعزلات بكتريا الرايزوبيوم المدروسة

\begin{tabular}{|c|c|c|c|c|c|c|c|c|c|c|c|c|c|c|c|c|c|c|c|c|c|c|c|c|c|c|c|c|c|}
\hline & hR & & & $\mathbf{P P}$ & & RhI & & & Pl & & & & & & hA & & & $\mathbf{R} \mathbf{1}$ & & & & $\mathbf{R h}$ & & & & $\mathbf{R h}$ & & & \\
\hline & & 1 & & 2 & & 32 & & b & & & 3 & 2 & 14 & 3 & 2 & 1 & 4 & 3 & 2 & 1 & 4 & 3 & 2 & 1 & 4 & 3 & 2 & 1 & \\
\hline & & & & + & & ++ & & - & & & + & + & t & & & + & + & + & + & + & + & + & + & + & + & + & + & + & الحركة \\
\hline+ & & & & + & & ++ & & - & $1^{+}$ & + & + & + & ++ & t & + & + & + & + & + & + & + & + & + & + & + & + & + & + & Catalase \\
\hline+ & & & & + & & ++ & + & + & $1^{+}$ & +- & + & + & ++ & + & & + & + & + & + & + & + & + & + & + & + & + & + & + & Oxidase \\
\hline+ & & & & + & 1 & ++ & + & - & & +- & + & + & ++ & + & + & + & + & + & + & + & + & + & + & + & + & + & + & + & تحليل اليوريا \\
\hline & & & & & & & & & & t & & - & & - & & - & - & - & - & - & - & - & - & - & - & - & - & - & استهلاك السترات \\
\hline & & 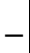 & & - & - & - & & & - & - & - & - & - & - & - & - & - & - & - & - & - & - & - & - & - & - & - & - & تحلل الجيلاتين \\
\hline- & & - & & - & - & -1 & & & & $-1-$ & -1 & - & $1-$ & - & $1-$ & - & - & - & -1 & - & - & - & - & - & - & - & - & - & Voges Proskaur \\
\hline & & & & 11 & & ++ & & ? & & & + & + & $1+$ & & & + & + & + & + & + & + & + & + & + & + & + & + & + & Mac-Conkey agar \\
\hline- & & & & - & & -- & & & & - & & - & & - & - & - & 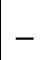 & - & - & - & - & - & - & - & - & - & - & - & انتاج H2S \\
\hline 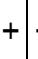 & & 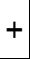 & & + & & ++ & & & & & & + & $1+$ & & & + & + & + & + & + & + & + & + & + & + & + & + & + & انتاج الاندول \\
\hline & & & & 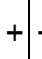 & & ++ & & + & & & & & & & & + & + & & + & + & + & + & + & + & + & + & + & + & انتاج الحامض من الكلوكوز \\
\hline & & & & & & ++ & & 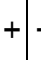 & & & + & & & & & & + & & + & + & + & + & + & + & + & + & + & + & ض من الرامذ \\
\hline
\end{tabular}




\begin{tabular}{|c|c|c|c|c|c|c|c|c|c|c|c|c|c|c|c|c|c|c|c|c|c|c|c|c|c|c|c|c|c|c|c|c|c|c|}
\hline+ & + & & ++ & ++ & -1 & + & & - & & & & & & & & & & & + & & & + & + & + & + & + & + & + & + & + & + & + & + & التو \\
\hline+ & & & 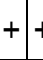 & + & & 1 & + & & & & & & & & & + & & $\mathrm{r}$ & & + & + & & & & & & & & & & & & + & \\
\hline+ & & + & ++ & ++ & & + & + & - & + & & & & & & & + & & + & & + & & & & & & & & & $x^{-1}$ & & + & + & T & 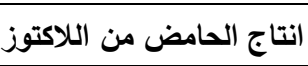 \\
\hline & & + & & ++ & + & & ( & & & & & & & & & + & & & & + & & & & & & & & & & & & & & \\
\hline
\end{tabular}

(+)(النتيجة الايجابية للاختبار (-) النتيحة السلبية للاختبار +(+

\section{اختبار مقاومة وحساسية البكتيريا المعزولة من العقد الجذريـة للمضادات الحيوية}

\section{Resistance and Sensitivity Test of Bacteria Isolated from Root Nodules to Antibiotics}

تمت دراسة تاثير عشرة من المضـادات الحيوية على مقاومة وحساسية بكتيريا الرايزوبيوم المعزولة من العقد الجذرية للنباتات

البقولية كما هو واضتح في الجدول رقم (6).

يبين الجدول (6) ان مجاميع بكتيريـا الرايزوبيا المعزولـة من العقد الجذريـة للنباتات البقولية تختلف في درجة مقاومتها

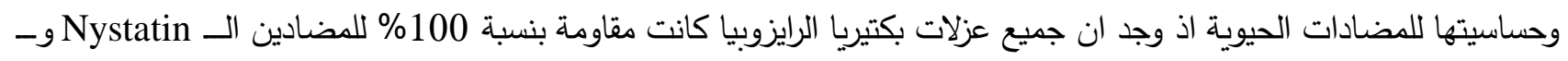
Amoxicillin العزلات المدروسـة بينما المضـادات الحيوية الاخرى فقد تباينت مقاومتها كنسـبة مئوية من قبل مجاميع بكتيريا الرايزوبيوم المعزولة

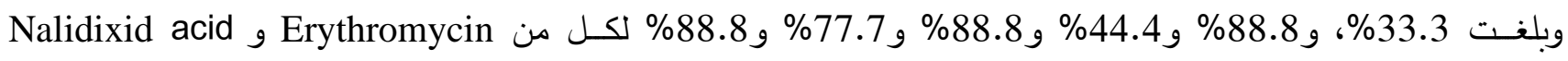

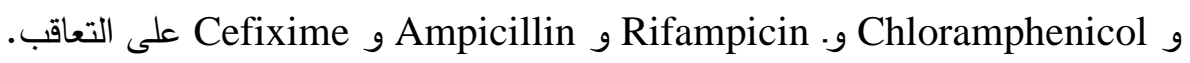
بالاضـافة الى ذلك فان مجاميع بكتيريا الرايزوبيا المعزولة من العقد الجذرية في المناطق المختلفة المشـمولة بالدراسـة تتباين

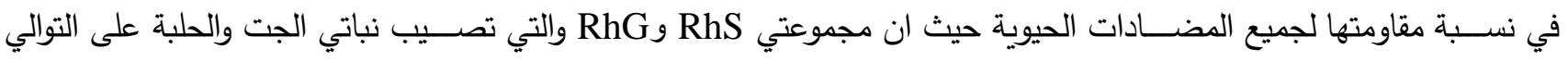

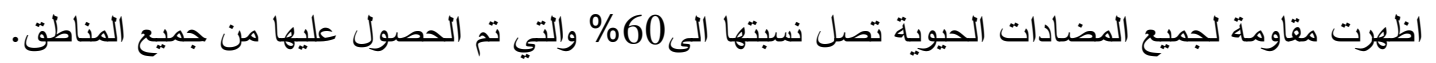

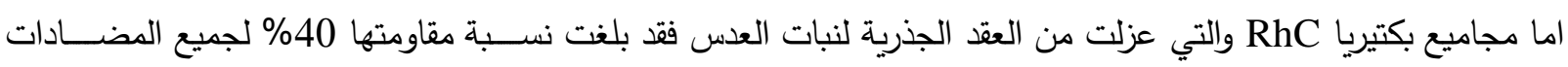

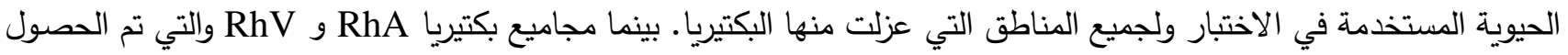

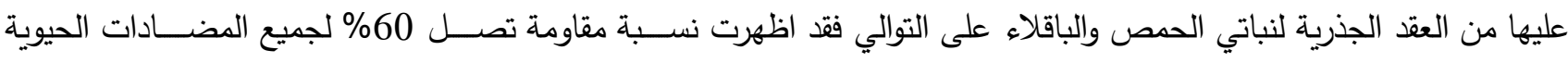

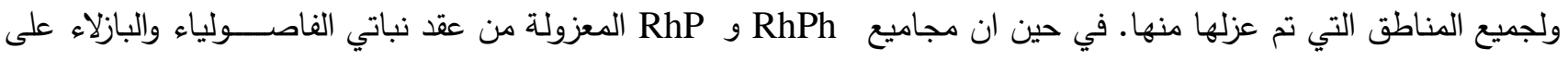

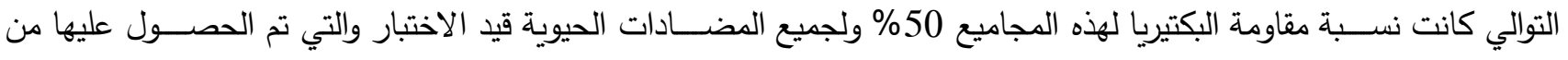

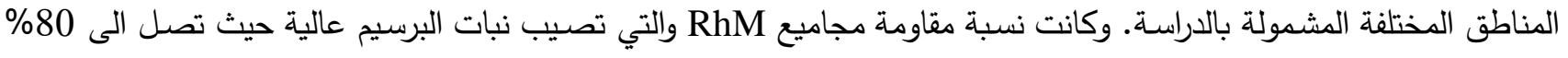

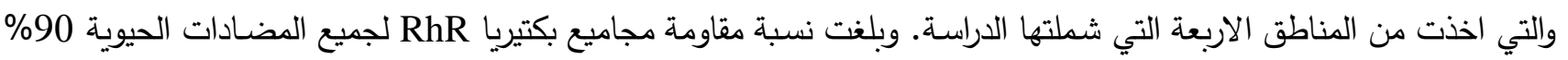

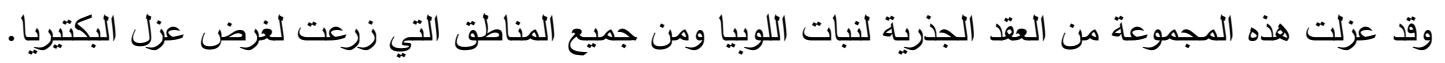

جدول رقم (6) مقاومة وحساسية بكتيريا الريزوبيوم المعزولة من عقد البقوليات للمضادات الحيوية

\begin{tabular}{|c|c|c|c|c|c|c|c|c|c|c|c|c|c|c|c|c|c|c|c|c|c|c|c|c|c|c|}
\hline \multicolumn{24}{|c|}{ مجاميع بكتيريا الرايزوبيوم المستخدمة في الدراسة حيث تضم كل مجموعة اربعة عزلات } & \multirow{3}{*}{$\begin{array}{l}\text { التهائي } \\
\text { التركيز }\end{array}$} & \multirow{3}{*}{ المضادات الحيوية } & \multirow{3}{*}{ ت } \\
\hline \multicolumn{2}{|c|}{ RhR } & \multicolumn{3}{|c|}{$\mathbf{R h P}$} & \multicolumn{2}{|c|}{ RhM } & \multicolumn{3}{|c|}{$\mathbf{R h P h}$} & \multicolumn{3}{|c|}{$\mathbf{R h V}$} & \multicolumn{3}{|c|}{$\mathbf{R h A}$} & \multicolumn{3}{|c|}{$\mathbf{R h C}$} & \multicolumn{2}{|c|}{ RhG } & \multicolumn{3}{|c|}{ RhS } & & & \\
\hline \begin{tabular}{l|l|l|l|l|l}
4 & 3 & 2
\end{tabular} & \begin{tabular}{l|l}
2 & 1
\end{tabular} & 43 & \begin{tabular}{l|l|l}
3 & 2
\end{tabular} & 14 & 43 & \begin{tabular}{|l|l}
2 & 1
\end{tabular} & 14 & 32 & 21 & 4 & 32 & & $4: 3$ & \begin{tabular}{l|l}
3 & 2 \\
2
\end{tabular} & 1 & 43 & 2 & 14 & & \begin{tabular}{l|l}
2 & 1
\end{tabular} & 4 & 32 & 1 & & & \\
\hline $\mathrm{R} / \mathrm{R} / \mathrm{R}$ & $\mathrm{R} R$ & $\mathrm{~S} S$ & $S$ & $\mathrm{~S} / \mathrm{H}$ & $\mathrm{R}$ & $\mathrm{R} R$ & $S$ & & $S$ & $S$ & $\mathrm{~S} S \mathrm{~S}$ & & $S:$ & & $S$ & $\mathrm{~S} S \mathrm{~S}$ & $S$ & $S$ & $S$ & S S & & & $S$ & 10 & Tetracycline & 1 \\
\hline \begin{tabular}{l|l}
$S$ & $S$ \\
\end{tabular} & $\mathrm{~S} S$ & $\mathrm{~S} S$ & $S \mid$ & $\mathrm{S}$ : & $R$ & $\mathrm{R} R$ & $\mathrm{~s}$ & $s: s$ & $S$ & $\mathrm{~S}$ & \begin{tabular}{l|l}
$S$ & $S$
\end{tabular} & $S$ & $\mathrm{~S}$ & $S \mid S$ & $S$ & $\mathrm{R} R$ & $\mathrm{R}$ & $\mathrm{R} S$ & & $\mathrm{~S} S \mathrm{~S}$ & $\mathrm{~S}$ & \begin{tabular}{l|l}
$S$ & $S$
\end{tabular} & $S$ & 20 & Streptomycin & 2 \\
\hline
\end{tabular}




\begin{tabular}{|c|c|c|c|c|c|c|c|c|c|c|c|c|c|c|c|c|c|c|c|c|c|c|c|c|c|c|}
\hline $\mathrm{R} \mid \mathrm{I}$ & $\mathrm{R} / \mathrm{R}$ & $\mathrm{R} S$ & & $\mathrm{~S} / \mathrm{S}$ & $\mathrm{R}$ & $\mathrm{R} / \mathrm{R}$ & $R$ & $S$ & 5 & $S$ & & $R$ & $\mathrm{R} S$ & $S$ & $S \mid$ & $S \mathrm{~S}$ & & $\mathrm{~S} S$ & $\mathrm{~S} S$ & $S S$ & $\mathrm{~S}$ & $\mathrm{~S} S$ & $\mathrm{SS}$ & 15 & Erythromycin & 3 \\
\hline $\mathrm{R} \mid \mathrm{I}$ & $\mathrm{R} / \mathrm{R}$ & & $R$ & $\mathrm{R} / \mathrm{R}$ & & & $R$ & $S:$ & $S$ & $S$ & & $R$ & $\mathrm{R} R$ & $\mathrm{R}$ & $\mathrm{R}$ & $\mathrm{R} R$ & $\mathrm{R} \mid \mathrm{I}$ & $\mathrm{R} / \mathrm{R}$ & $\mathrm{R}$ & $\mathrm{R} R$ & $R$ & $\mathrm{R} R$ & $\mathrm{R}$ & 30 & Nalidixic acid & 4 \\
\hline $\mathrm{R}$ & $\mathrm{R} / \mathrm{R}$ & & $\mathrm{S}$ & $\begin{array}{ll}S \\
S\end{array}$ & $\mathrm{~S}$ & $\begin{array}{ll}S & S\end{array}$ & & $\mathrm{~S}$ & $S$ & $\mathrm{~S}$ & & $\mathrm{~S}$ & \begin{tabular}{l|l}
$\mathrm{S}$ & $\mathrm{R}$
\end{tabular} & $\mathrm{R}$ & & $\mathrm{R} S$ & $\mathrm{~S}$ & $S S$ & $\mathrm{R} F$ & & $\mathrm{R}$ & $\mathrm{R} R$ & $\mathrm{R}$ & 30 & Chloramphinicol & 5 \\
\hline $\mathrm{R}$ & $\mathrm{R} / \mathrm{R}$ & $\mathrm{R} R$ & $R$ & $\begin{array}{ll}\mathrm{R} & \mathrm{R}\end{array}$ & $\mathrm{R}$ & $\mathrm{R} R$ & $\mathrm{R}$ & $\mathrm{R} \mid$ & $\mathrm{R}$ & $\mathrm{R}$ & & $\mathrm{R}$ & $\mathrm{R} R$ & $\mathrm{R}$ & $\mathrm{R} \mid$ & $\begin{array}{lll}\mathrm{R} & \mathrm{R}\end{array}$ & $\mathrm{R} / \mathrm{I}$ & $\mathrm{R} / \mathrm{R}$ & $\mathrm{R} F$ & & $R$ & $\mathrm{R} R$ & $\mathrm{R}$ & 50 & Nystatin & 6 \\
\hline $\mathrm{R}$ & $\mathrm{R}$ & $\mathrm{R} R$ & $R$ & $\begin{array}{ll}\mathrm{R} & \mathrm{R}\end{array}$ & $\mathrm{S}$ & $\begin{array}{ll}S & S\end{array}$ & $\mathrm{~S}$ & $\mathrm{R} \mid$ & & $\mathrm{R}$ & & $\mathrm{S}$ & $\begin{array}{lll}S & S\end{array}$ & $\mathrm{~S}$ & $\mathrm{~S}$ & $\begin{array}{l}S \\
S\end{array}$ & $\mathrm{~S}$ & $S S$ & $\mathrm{~s} s$ & & $S$ & S S & $\mathrm{S} S$ & 50 & Rifampicin & 7 \\
\hline $\mathrm{R} \mid \mathrm{I}$ & $\mathrm{R} / \mathrm{R}$ & & $S$ & $\mathrm{~S} S$ & $\mathrm{R}$ & $\mathrm{R} / \mathrm{R}$ & $\mathrm{R}$ & $\mathrm{R}$ & $2 \mid \mathrm{R}$ & $R$ & & $R$ & $\mathrm{R} R$ & $\mathrm{R}$ & $\mathrm{R}$ & $\mathrm{R} S$ & $\mathrm{~S}:$ & $S S$ & $\mathrm{R}$ & & $\mathrm{R}$ & $\mathrm{R} R$ & $R$ & 50 & Ampicilin & 8 \\
\hline $\mathrm{R}$ & $\mathrm{R}$ & $\begin{array}{ll}\mathrm{R} & \mathrm{R}\end{array}$ & $R$ & $\begin{array}{ll}\mathrm{R} & \mathrm{R}\end{array}$ & $\mathrm{R}$ & $\mathrm{R} R$ & & $\mathrm{R}$ & & $\mathrm{R}$ & & $\mathrm{R}$ & $\mathrm{R} R$ & $\mathrm{R}$ & & $\mathrm{R} R$ & & $\begin{array}{ll}\mathrm{R} \\
\mathrm{R}\end{array}$ & $\mathrm{R} F$ & & $\mathrm{R}$ & $\begin{array}{ll}R \\
R\end{array}$ & $\mathrm{RP}$ & $\mathrm{R}$ & Amoxilin & 9 \\
\hline $\mathrm{R} \mid \mathrm{I}$ & $\mathrm{R} / \mathrm{R}$ & $\mathrm{R}$ & $R$ & $\mathrm{R} / \mathrm{R}$ & $\mathrm{R}$ & $\mathrm{R} \mid \mathrm{R}$ & 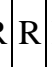 & $\mathrm{R}$ & & & $\mathrm{R}$ & & $\mathrm{R} R$ & & $\mathrm{R} \mid \mathrm{I}$ & $\mathrm{R} S$ & $\mathrm{~S}$ & $\mathrm{~S} S$ & $\mathrm{R} \mathrm{H}$ & $\mathrm{R} R$ & $\mathrm{R}$ & $\mathrm{R} R$ & $\mathrm{R}$ & 50 & Cefixime & 10 \\
\hline
\end{tabular}

(S) ظهور صفة الحساسية (R) ظهور صفة المقاومة

ذكر في احدى الدراسـات لــGauri واخرون [33] التي اختصت بدراسـة نمط المقاومة للمضـادات الحيوية في 85عزلة من بكتيريا الرايزوبيوم Trifolium alexandrinum التي تتمو بشكل واسع في الهند وذلك عند استخدام الباحثين عدد من المضـادات

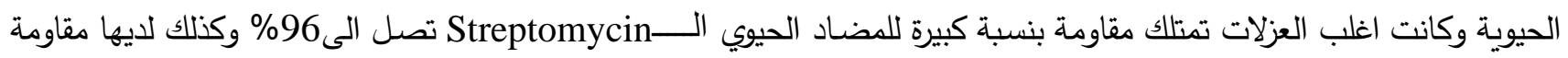

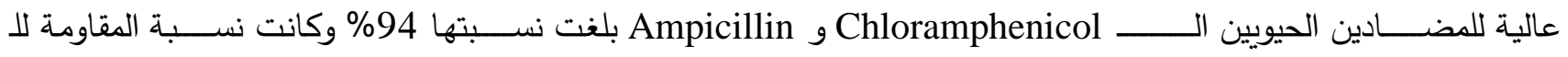

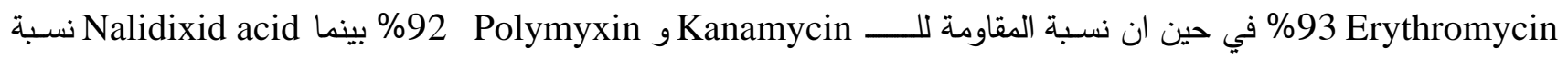

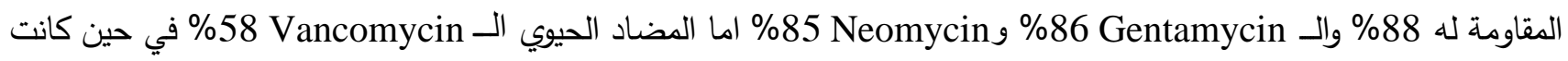

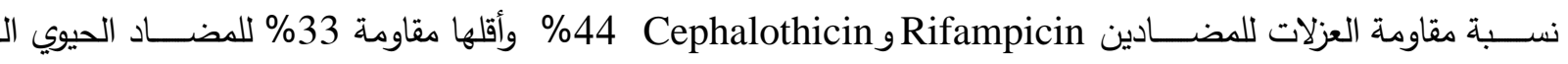

.Tetracyclin

تتقق هذه النتائج مع دراسـة اجريت على 48 سـلالة من بكتيريا Rhizobium japonicum لاختبار مقاومتها للمضــادات

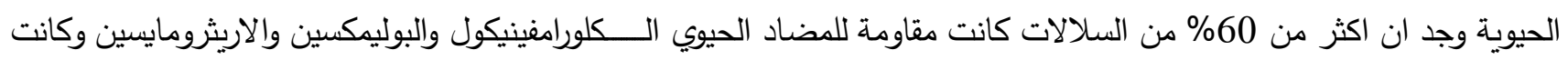
47 او اكثر من السلالات مقاومة للنيومايسين والبنسلين -G عند اختبارها بواسطة اقراص المضادات الحيوية [34]. وفي دراسة اجراها الباحثين Shama و Diwan سنة (2011) شملت عزل بكتيريا الرايزوبيا من عشرة نباتات بقولية مزروعة Phaseolus aureus, Phaseolus vulgaris, Arachis hypogaea, Dolichos) lablab, Glycine max, وهئسئي (Lathyrus sativa و Trigonella foenum graecum, Cicer arietinum, Vigna ungiculeta, Pisum sativum وثلاث انواع بقولية برية هي Mimosa pudica, Desmodium) triflorum و و Tephrosia purpurea تمو في الهند حيث تضـمنت الدراسـة اختبار الحساسية والمقاومة لثلاث عشرة عزلة بكثيرية تابعة للجنس .Rhizobium spp ولخمسـة من المضـادات

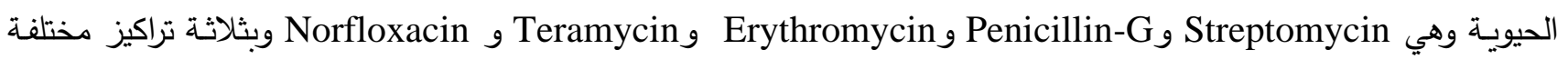

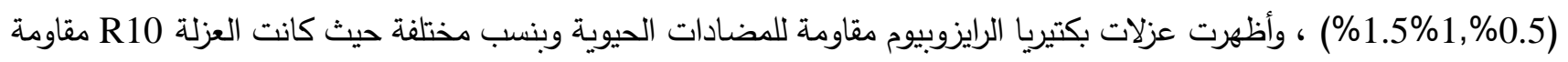

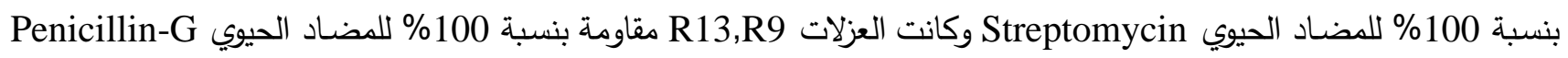
والعزلة R8 تمتلك مقاومة بنسـبة 100\% للمضــادمeramycin بينما العزلة R4 فقد كانت لها القدرة على مقاومة المضــاد الحيوي [35] بنسبة 100 Erythromycin 
وعند مقارنة نتائج اختبار الحساسية للمضادات الحيوية مع نتائج هذه البحوث يمكن الاستتتاج بان هنالك صفات مشتركة الى

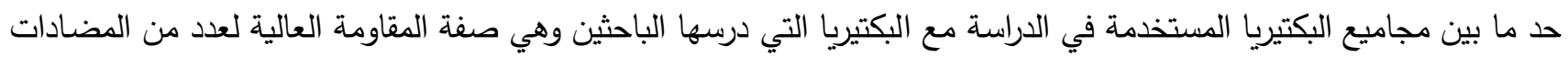

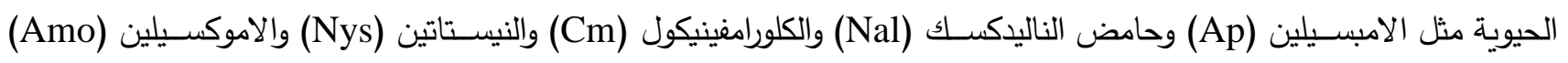

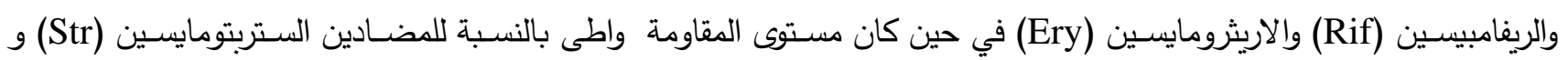
التتراسايكلين (Tc).

اختبار مقاومة وحساسية البكتيريا المعزولة من العقد الجذرية للمعادن الثقيلة Resistance and Sensitivity Test of Bcteria Isolated from Root Nodules to Heavy Metal

من خلال ملاحظة الجدول (7) وجد ان مجاميع بكتيريا الرايزبيوم والتي عزلت من العقد الجذريـة للنباتات البقولية كانت جميعها مقاومة لكل من كلوريد الكادميوم الثقيل كلوريد النيكل

$$
\text { ولجميع العزلات المدروسة. }
$$

كذلك أظهرت عزلات البكتيريا لمجموعة (RhC) اعلى نســبـة مقاومـة وهي 100\% لجميع املاح المعـادن الثقيلة بينما


والحلبة والحمص والباقلاء والفاصـولياء والبرسـيم والبازلاء واللوبيا على التوالي، ولجميع المناطق المشـمولة بالدراســة فقد كانت نسـبة

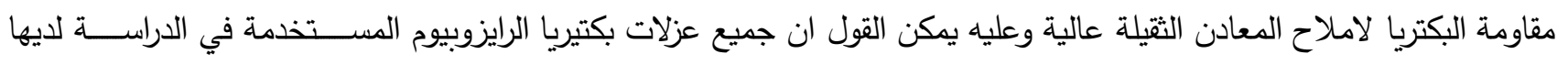
مقاومة متعددة لاملاح المعادن الثثيلة وتعتبر صفة المقاومة صفة شائعة في بكتيريا الرايزوبيوم. جدول رقم (7) مقاومة وحساسية بكتيريا الرايزوبيوم المعزولة من عقد النباتات البقولية للمعادن الثقيلة

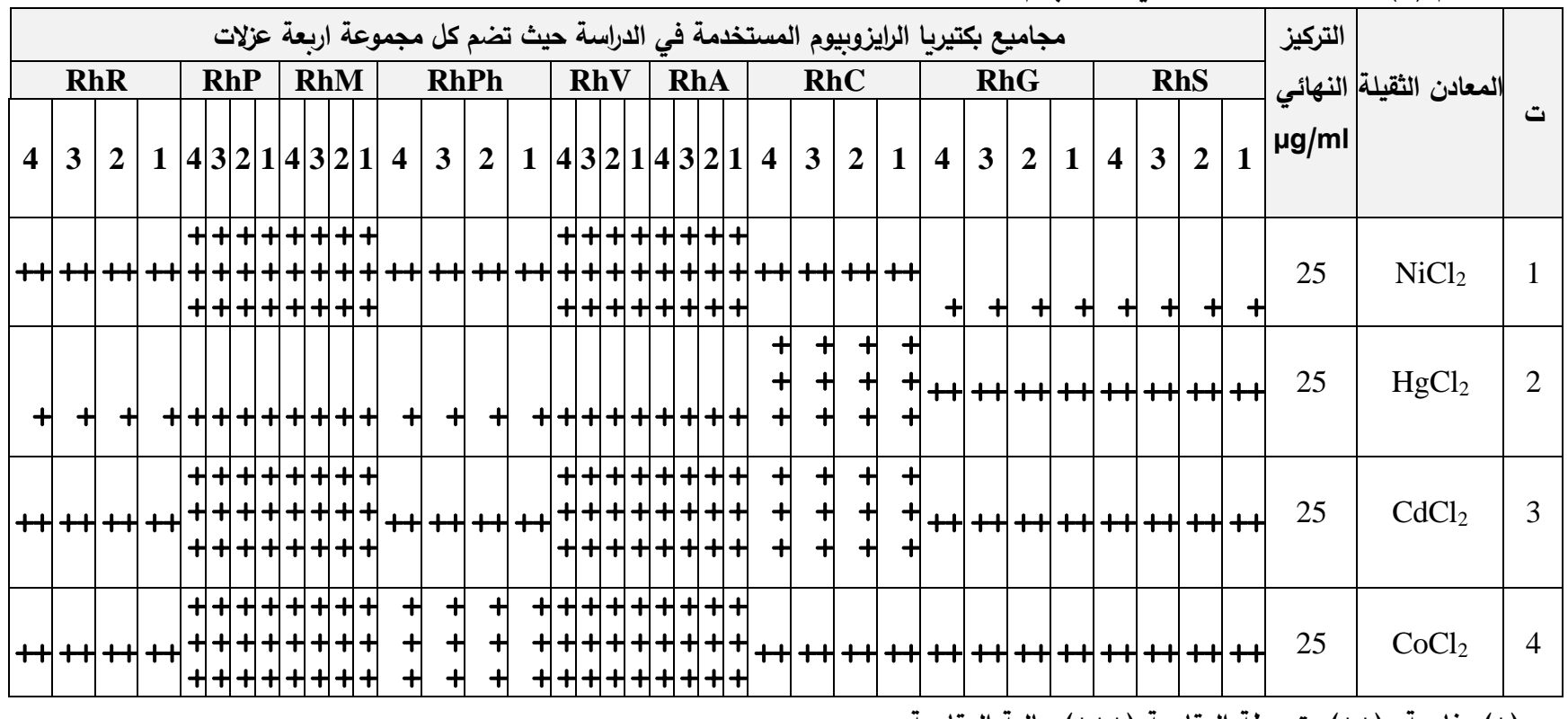
(+) مفاومة (++) متوسطة المقاومة (+++) عالية المقاومة

علما بان بكتيريا الرايزوبيوم قد تحمي نفسها من التاثير السام لاملاح المعادن الثقيلة من خلال عدد من الاليات منها : 1-

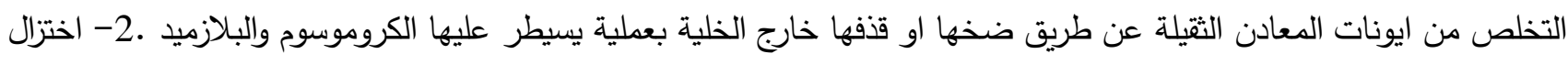
ايونات المعادن الثقيلة وتحويلها الى صورة اقل سمية .3- تكوين معقدات لايونات المعادن الثقيلة داخل الخلية [36]. 
بين الباحثان Paul واخرون [37] ان السـمية والتراكم الحيوي للمعادن الثقيلة في البيئة تؤثر بشـكل كبير على حياة الكائنات

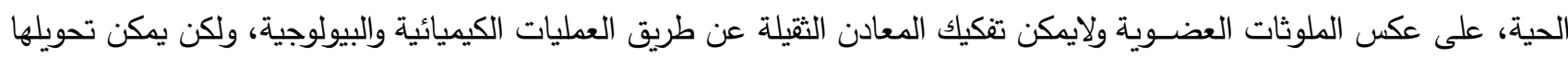
الى انواع اقل سمية، حيث قام هؤلاء الباحثين بعزل البكتيريا التي تتحمل وجود المعادن الثقيلة من مختلف المناطق الصناعية الملوثة

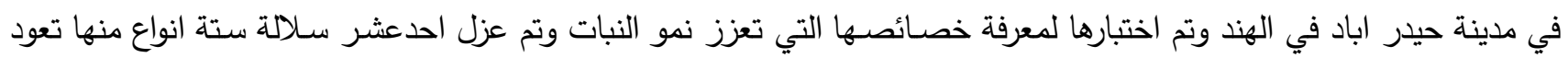

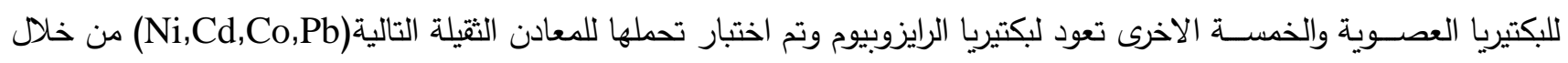

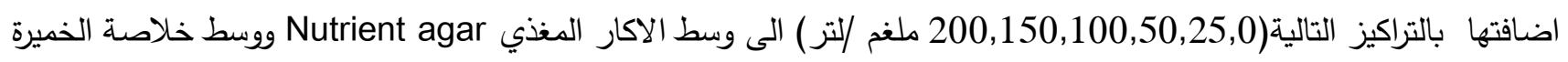

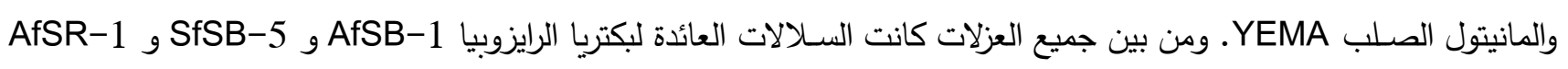

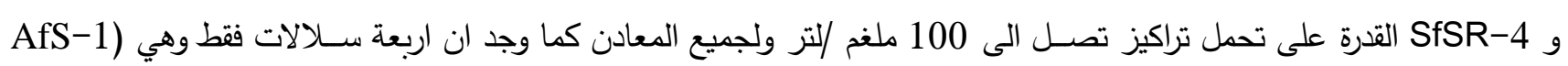

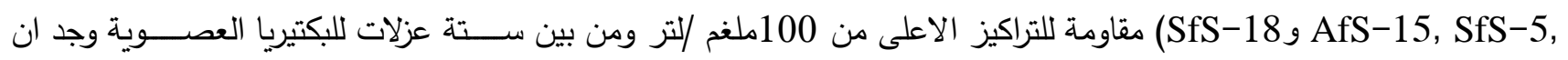

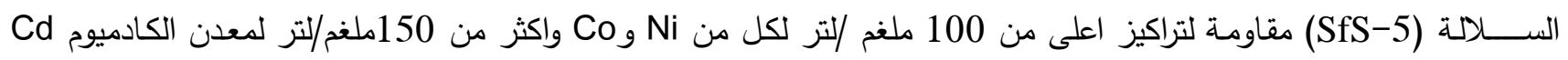

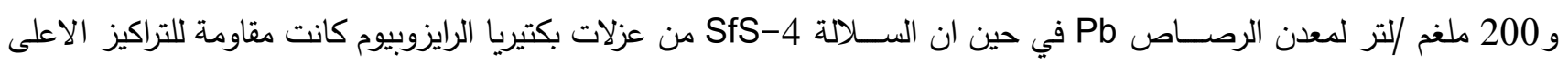

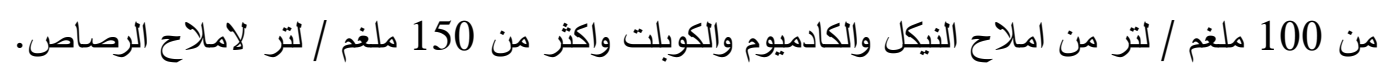

(Ni,Cd,Co,Pb (ان جميع سـلالات البكتيريا العصــوية وبكتيريا الرايزوبيوم المعزولة من التربة الملوثة بالمعادن الثقيلة اظهرت مقاومة لهذه المعادن عند التركيز 25 ملغم / لتر.

وفي دراســــة اجرها الباحثينRuiz-Diez واخرون [38] المتعلقة بعزل البكتيريا التكافلية من البقوليات النامية في تربة ملوثة بالزئبق في مدينة Almaden في اسبانيا لانتاج مجموعة من بكتيريا الرايزوبيا يمكنها التكيف بثكل جيد مع الظروف البيئية

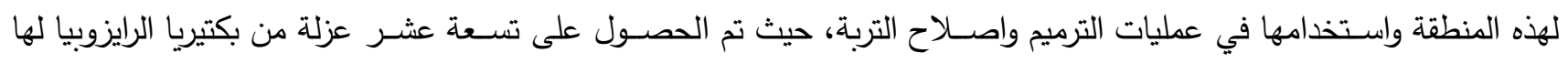

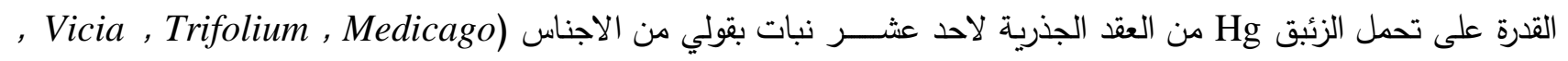
ثلاثة Phaseolus, Lupinus ثلاثة مجاميع اعتمادا على قدرتها على تحمل Hg وقد حدد التركيز المثبط الادنى والتراكيز الفعالة التي تتتج انماط تحمل الزئئق

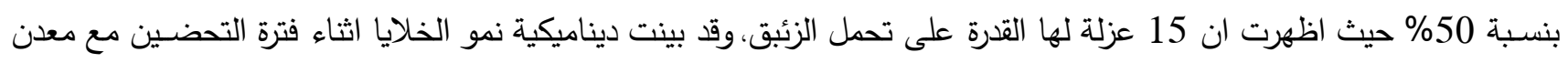

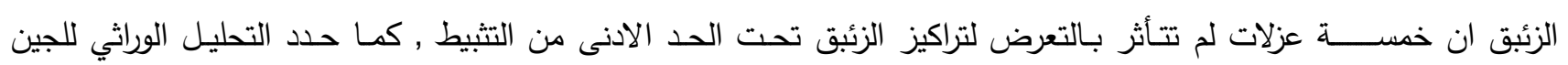

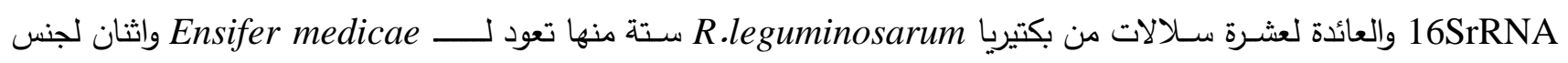
B.canariense وسـلالة واحدة للجنس Rod C وان تلقيح النباتات المضيفة وتحليل جينات مثرة ان معظمها تتأثر عضويا. مقاومة الاحياء المجهرية في التربة تتطور نتيجة التأثير السام للمعادن الثقيلة ومن المكن ان يحدث هذا التطور في البكتيريا

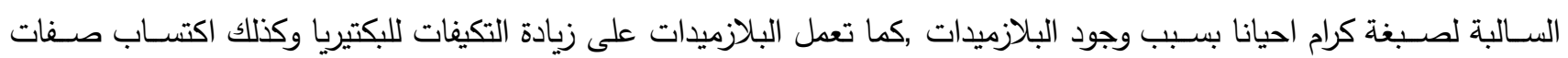
وراثية جديدة بسبب التلوث [39].

عزل وتوصيف الـ DNA البلازميدي من مجاميع بكتيريا الرايزوبيا قيد الدراسة باستخدام الترحيل الكهربائي في هلام الاكاروز Isolation and characterization of plasmid DNA from groups of rhizobia bacteria under study using electrophoresis in agarose gel 
تظهر حزم الـ DNA البلازميدي في الاعمدة (5,4,3,2,1) المحتوى البلازميدي للمجاميع البكتيرية RhS وRhM وRhG

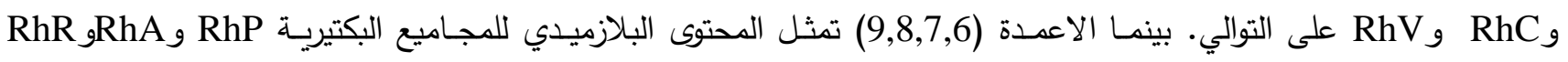
و RhPh، على التوالي.

كما يوضح الثكل (2) احجام حزم الـ DNA البلازميدي التي ظهرت بصورة واضحة ومميزة لقربها من حفر هلام الاكاروز

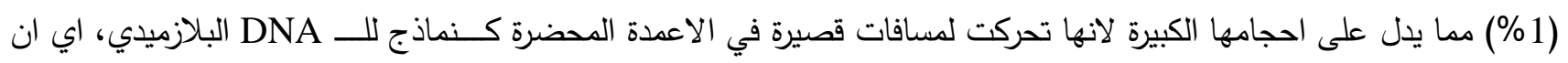

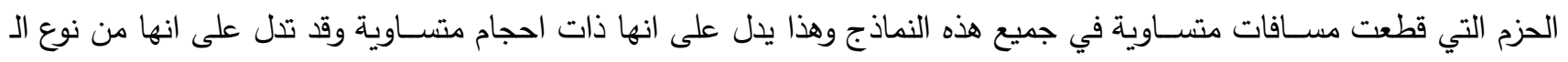

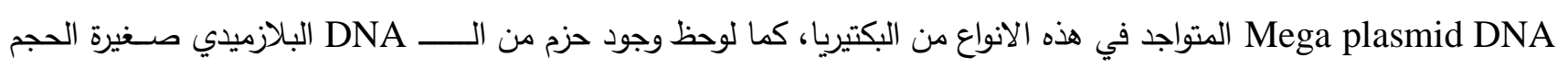
قطعت مسافة طويلة في الهلام وهي عبارة عن بلازميدات من نوع اخر موجودة ايضا في هذه الانواع من البكتيريا. يوضح الثكل (2) نتائج الترحيل الكهربائي لـحتوى الـ DNA البلازميدي في هلام الاكاروز •

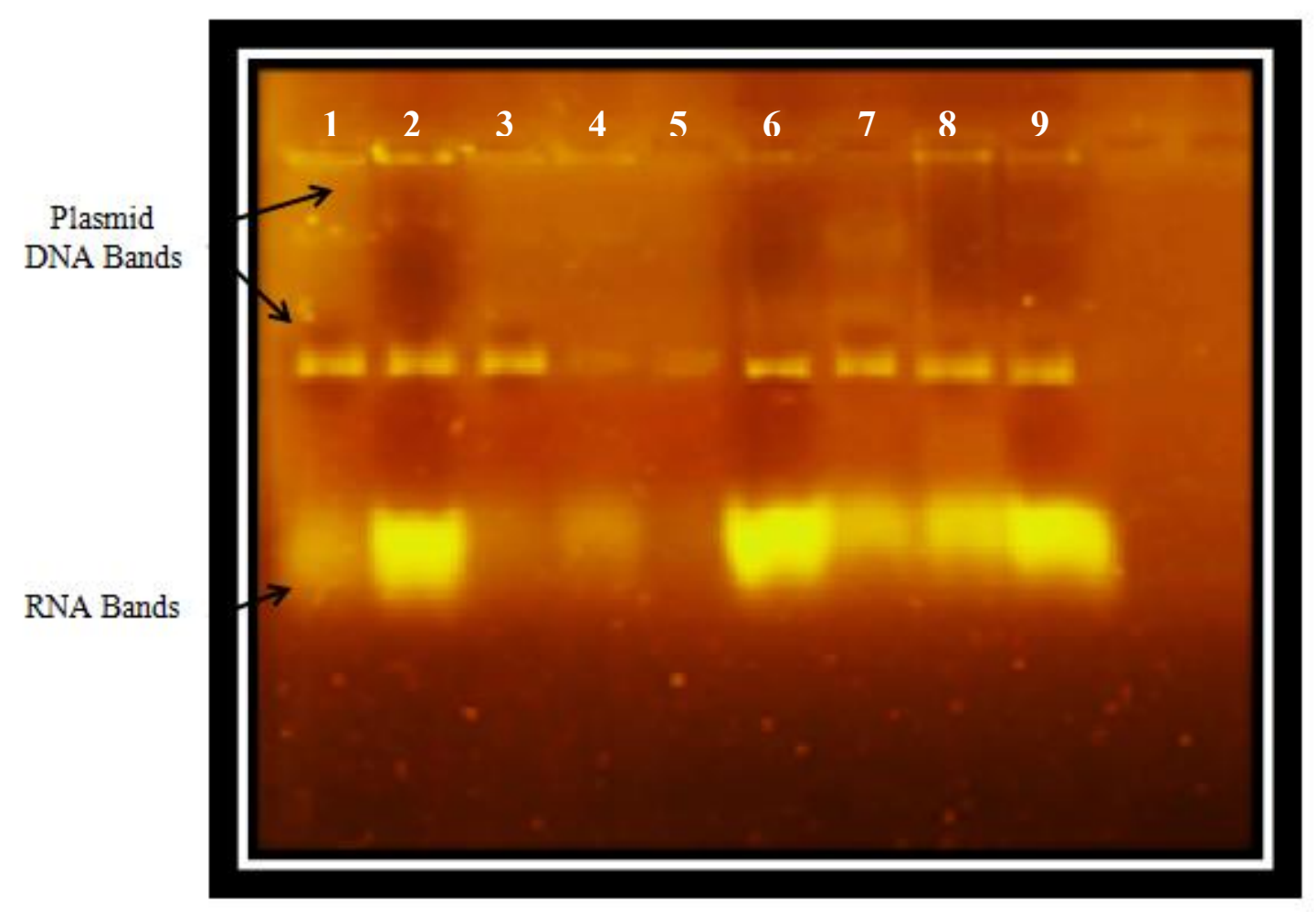

شكل (2) الترحيل الكهربائي لمحتوى الـ DNA البلازميدي في هلام الاكاروز (1\%) لمجاميع بكتيريا الريزوبيا قيد الدراسة.

بناء على ذلك يمكن القول ان هناك نوعين من البلازميدات ضمن محتوى الـ DNA البلازميدي لعزلات بكتيريا الرايزوبيوم المدروســــة الاول كبير في الحجم يدعى Mega plasmid يمثل البلازميدات التكافلية التي تحمل جينات تكوين العقد وتثبيت

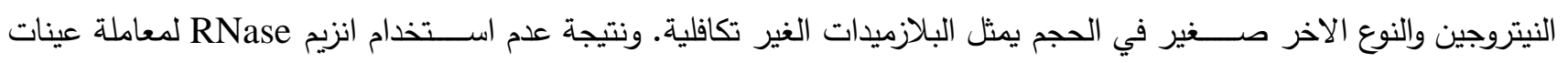

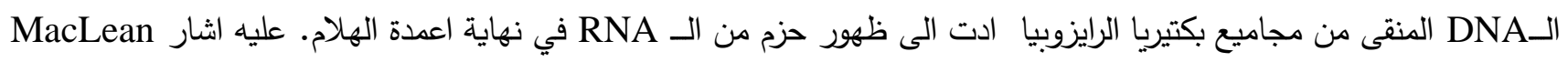

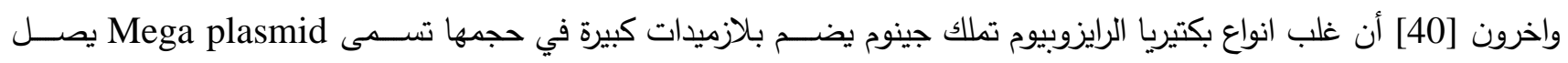
حجمها احيانا الى 1500kbp حيث تقع على هذه البلازميدات الجينات التي تثــفر عملية تكوين العقد الجذرية وتتبيت النيتروجين. 
مثل بكتيريا R.etli السريعة النمو تمتلك ستة بلازميدات صغيرة وهي تمثل ثلث حجم الجينوم الكلي الذي يصل حجمه الى 6.5Mb بينما بكتيريا Bradyrhizobium البطيئة النمو فإنها تفتقر لهذا النوع من البلازميدات. الاستنتاجات

تثـير اختبارات التخصـص العائلي للبكتيريا امكانية اسـتخدامها كـــــأدلة في عملية التشـخيص أما اختلاف مجاميع بكتيريا الرايزوبيا المعزولة من العقد الجذرية لنباتات البرســـيم والجت والحلبة والعدس والحمص والباقلاء والفاصـــــلياء والبازلاء واللوبيا في

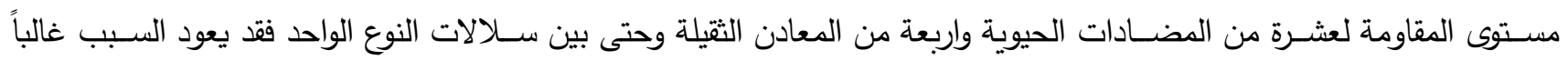
لاختلاف البيئة التي عزلت منها. من ناحية اخرى تم تأكيد وجود نوعين من البلازميدات مختلفة في الحجم استتادا الى نتائج الترحيل الكهربائي في هلام الاكاروز (1\%) لمحتوى الـ DNA البلازميدي. ومن خلال ملاحظة نمو المستعمرات لمجاميع بكتيريا الرايزوبيا المعزولة على وسط YEMA تبين انها تنتج كميات من السكر المتعدد الخارج خلوي وبنسب مختلفة حتى عند حفظها بدرجة حرارة

1- Iyer, B. and Rajkumar, S. Rhizobia. In Reference Module in Life Sciences, Elsevier, Nirma University, P: 1-20(2018).

2- Pervin, S.; Jannat, B.; Alsanjee, S. And Farzana, T. Turkish J. of Agriculture-Food Sci. Technol., 5(1): 14-17 (2017) .

3- Setu, L.J.; Ahmed, B. and Kibria, K.Q. Int. J.Res.Anal.Rev., 6(2): 519-527 (2019).

4- Khalil, N.I. and Abdul Ghafoor, A. Tikrit J. Pure Sci., 16(2): 188-193(In Arabic)(2011).

5- Graham, P.H. Can. J. Microbiol., 38(6): 475-484 (1992) .

6- Dhull, S .; Singh.K. and Gera, R.J.Chem.Sci.Rev.Lett., 7(26): 692-697 (2018).

7- Talaro, K. and Talaro, A. Foundations in microbiology.3th ed, McGraw-Hill companies, Inc., U. S. A.(1999).

8- Graham, P.H. Appl. Microbiol., 17(5): $769-770$ (1969).

9- Vincent, J.M. A Manual for the Practial Study of Root Nodule Bacteria.IBP Handbook No.15. Oxford: Blackwell Scientific Publications, Oxford, p. 113-131(1970).

10- Fahraeus, G. J. Gen. Microbiol., 16(2): 374-381 (1957).

11- Grant, A.J. and Pittard, J. J.Bacteriol., 120(1): 185-190(1974).

12- Ahmed, K.D. The Positive Control of ilvc expression in E.coli K-12. Ph. D. Thesis, Univ. Durham, England(1989).

13- Singh, B.; Kaur, R. and Singh, K. Afr. J. Biotech., 7(20): 3671-3676 (2008).

14- Deora, G.S. and Singhal, K. Int. Sci. J., 3(2): 132-136 (2010).

15- Chhetri, T.K.; Subedee, B.R. and Pant, B.Nep. J. Biotechnol., 7(1): 39-49 (2019).

16- Wadhwa, Z.; Srivastava, V.; Rani, R.; Tanvi; Makkar, K. and Jangra, S. Int. Curr. Microbiol. Appl. Sci., 6(11): 2880-2893 (2017).

17- Cappuccino, J.G. and Sherman, N. Microbiology a laboratory Manual. $5^{\text {th }}$ ed, Addison Wesley Longman, Inc., p.133-145(1999).

18-Benson, H.J. Microbiological, $8^{\text {th }}$ ed, McGraw Hill Companies, Inc., p.130-155(2002).

19-Baron, E.J.; Pezlo, M.T. and Delamaza, L.M. (1997) Color Atlas of Diagnostic Microbiology. Mosby-Year Book, United Startes of America, p.25-92(1997). 
20-Atlas, R.M.; Brown, A.E. and Parks, L.C. Laboratory Manual of Experimental Microbiology. Mosby-Year Book, Inc., St-Louis, U.S.A.(1995).

21- Geurts, R. and Basseling, T. The plant cell, 14: 239-249 (2002).

22-Selami, N.; Auriac, M.C.; Catrice, O.; Capela, D.; Harche, M.K. and Timmers, T. J. Plant-Soil, 379(1-2): 109-119 (2014).

23-Wong, C.H.; Pankhurst, A.; Kondorosi, and Broughton, W.J. J. Cell Biol., 97: 787-794 (1983).

24- Hussain, M.; Ashraf, M.; Saleem, M. and Hafeez, F.Y. Pak. J. Agri. Sci., 39: 32-34 (2002).

25- Sajjad, M.; Malik, T.A.; Arshad, M.; Zahir, Z.A.; Yusuf, F. and Rahman, S. Int. J. Agri. Biol., 10(5): 505-510 (2008).

26- Deka, A.K. and Azad, P. Legume Res., 29(3): 209-212 (2006).

27- Shahzad, F.; Shafee, M.; Abbas, F.; Babar, S.; Tariq, M.M. and Ahmad, Z. J. Ani. Pla. Sci., 22(2): 522-524 (2012).

28- Roychowdhury, D.; Paul, M. and Banerjee, S.K. Euro. J. Biotech. Biosci., 3(12): 26-29 (2015).

29- Elzanaty, A.M.; Hewedy, O.A.; Nagaty, H.H. and Abd Elbary, M.I. J. Bioeng. Biomed. Sci., 5(1): 1-8 (2015).

30- Al-Mujahidy, S.M.J.; Hassan, M.M.; Rahman, M.M. and Mamun-or-Rashid, A.N.M. Int. Res. J. Biotech., 4(7): 117-123 (2013).

31- Hamza, T.A. and Alebejo, A.L.Int . J . Novel Res. in Interdisciblinary Studies, 4(4): 1-7 (2017).

32- Kumari, N.N.B.; Nagaraju, B. and Mallkarjuna, K. Inn. Int. J. Med. Pharm. Sci., 2(2): 8-13 (2017).

33- Gauri; Singh, A. K.; Bhatt, R.P.; Pant, S.; Bedi, M.K. and Naglot, A. J. Agri. Technol., 7(6): 1705-1723 (2011).

34- Cole, M.A. and Elkan, G.H. J. Appl. Environ. Microbiol., 37(5): 867-870 (1979).

35- Shama, S. and Diwan, R. J. Ecobiotech., 3(4): 13-15 (2011).

36- Khan, M.S.; Zaidi, A.; Wani, P.A. and Oves, M. J. Environ. Chem. Lett., 7: 1-19 (2009).

37- Paul, M.N.; Triveni, S.; Latha, P.C.; Patnaik, M.C. and Rao, A.M. Int. J. Curr. Microbiol. Appl. Sci ., 7(8): 3583-3591 (2018).

38- Ruiz-Diez, B.; Quinones, M.A.; Fajardo, S.; Lopez, M.A.; Higueras, P. and Fernanez-Pascual, M. Appl. Microbiol. Biotechnol., 96(2): 543-554 (2012).

39- Silver, S. Plasmid, 27(1): 1-3 (1992).

40- MacLean, A.M.; Turlough, M.F. and Michael, J.S. Plant Physiol., 144(2): 615-622 (2007). 